Equine Trophectoderm Cells and Their Role in Fetal-Maternal Recognition.

$$
\text { Susana Paola Bonometti Vasquez }
$$

Thesis submitted to the faculty of the Virginia Polytechnic Institute and State University in partial fulfillment of the requirements for the degree of

\author{
Master of Science \\ In \\ Animal and Poultry Sciences
}

Sally E. Johnson (chair)

Alan Ealy

James Knight

December 4, 2018

Blacksburg, VA

Keywords: hepatocyte growth factor, proliferation, prostaglandin, trophectoderm

Copyright 2018 Susana Bonometti 


\section{Equine Trophectoderm Cells and Their Role in Fetal-Maternal Recognition.}

\section{Susana Paola Bonometti Vasquez}

\section{ACADEMIC ABSTRACT}

Establishment and maintenance of a successful pregnancy requires signaling from the embryo to the mare, a process known as maternal recognition. Six days after fertilization, the trophectoderm (TE), a placenta precursor is formed. Signals emanating from the TE to the uterine environment are critical to maternal recognition of pregnancy. The identity of factors necessary for this process remain unknown. A novel equine induced trophoblast cell line (iTr) that closely mimics the genotype and phenotype of native equine TE was created. Transcriptome analysis of iTr revealed increased expression of growth factor (GF) receptors for Epidermal GF (EGF), Hepatocyte GF (HGF), Fibroblast GF-2 (FGF-2) and Insulin GF (IGF-1), suggesting these GF may be important targets during TE development in the early embryo. We hypothesized that treatment of iTr cells with these GF would induce changes in cell proliferation and expression of genes likely involved in maternal recognition. The objectives of this experiment were to evaluate the effect of these GFs on iTr mitotic response and regulation of genes involved in steroidogenesis.

Equine iTr cells $(\mathrm{n}=3)$ were cultured with $10 \mathrm{ng} / \mathrm{mL}$ EGF, HGF, FGF-2 or IGF-1 for $24 \mathrm{hr}$, with 5-ethynyl-2'-deoxyuridine (EdU) supplementation during the final $2 \mathrm{hr}$. Subsequently, cells were fixed and EdU positive and total nuclei were enumerated. A parallel plate of iTr cells was treated in a similar manner and lysed for total RNA isolation. Quantitative PCR using gene-specific primers for CYP11A1, PTGS2, PTGES2, and PTGES3 was performed. Data were analyzed by ANOVA with Tukey's post hoc adjustment using the GLM procedure of SAS. Treatment with EGF, FGF-2, HGF, and IGF-1 increased $(\mathrm{P}<0.05)$ iTr proliferation from control levels of 25.33 
$\pm 1.03 \%$ to $38.58 \pm 1.61 \%, 45.50 \pm 2.94 \%$, and $38.23 \pm 2.01 \%$ respectively. The $2-\Delta \Delta \mathrm{CT}$ method was used to calculate the fold change (FC) using GAPDH as the reference gene for normalization. Expression of CYP11A2, PTGES2, and PTGES3 was not affected by GF, as measured by qPCR. By contrast, PTGS2 transcript abundance increased $(\mathrm{P}<0.05)$ following FGF-2 $(\mathrm{FC}=3.327 \pm 0.8291)$ and $\mathrm{HGF}(\mathrm{FC}=11.88 \pm 4.572)$ treatment. These results indicate that FGF-2 and HGF may simultaneously induce proliferation and prostaglandin production by TE cells. The combined results of these experiments will improve our understanding of TE morphogenesis and its response to uterine-derived growth factors.

KEY WORDS: equine, maternal recognition of pregnancy, trophectoderm 


\section{Equine Trophectoderm Cells and Their Role in Fetal-Maternal Recognition. Susana Paola Bonometti Vasquez}

\section{GENERAL AUDIENCE ABSTRACT}

Establishment and maintenance of a pregnancy requires that the mare uterus recognize the presence of the embryo, a process known as maternal recognition of pregnancy. The trophectoderm (TE) are cells on the outer layer of the embryo formed six days after fertilization, which later give origin to the placenta. The TE sends signals from the embryo to the uterus, that are very important for the mare's recognition of the embryo's presence. The specific nature of these signals are still unknown in the horse. A cell line (iTr) very similar in aspect and genes to the horse's native TE has been created in our laboratory. A set of comparative assays have showed that, during the developmental stage of maternal recognition, both the horse TE and the iTr cells share significant identity, and have receptors for the same set of growth factors (GF), suggesting these GF are important for early embryo development and potentially involved in the signaling process of maternal recognition.

We proposed that treatment with these GF would induce iTr cells to proliferate and express signals likely involved in maternal recognition in horses. The objectives of this experiments were to evaluate the effect of EGF, HGF, FGF-2 and IGF-1 on iTr cells by measuring proliferation and cellular mechanisms of maternal recognition already established in in other species.

Equine iTr cells were cultured with different GF and right before analysis a fluorescent dye that stain dividing cells was added in order to measure the proliferation. Equivalent cell cultures were used to evaluate if the treatment affected the production of hormones involved in signaling maternal recognition. Treatment with all GF induced higher cell proliferation, but HGF also increased the production of one enzyme that participates in producing a very important 
hormone (prostaglandin $\mathrm{E}_{2}$ ). The combined results of these experiments add to our understanding of maternal recognition in horses.

KEY WORDS: equine, maternal recognition of pregnancy, trophectoderm. 


\section{ACKNOWLEDGEMENTS}

The first in the list are my Mom and sister Francesca because they always believe in me. To Bruno, my husband who has been so supportive and helpful in every aspect, without him I wouldn't have done it. Gracias Bichito!! To my lab mattes Patricia Helsel, Alicia Pyne, Amanda Brandt and Jamea Kidrick! Girls you have been amazing, very supportive and fun to work with. Just one of us had lab experience so it was nice to see how we grew after a year, when at the beginning we were so scared to kill the cells in the plates or scrape too hard.

Yue Lu, Amanda, Sarah McCoski and Lydia Wooldridge you have been the most supportive and patient teachers ever, I can’t thank you enough!!!! My undergrads Jenny Schlenker, Ana Gibbons and Natalie Lovelace, thank you so much for your help, I had a great time with you girls. Also to my friend Rawan and Jenny that always cheered me up in the bad moments and always trust and believe in me and finally to Dr Johnson, my advisor, and Dr Ealy for give me all their support, knowledge, crazy ideas, I learned a lot from both of you. Muchas gracias a todos!! 


\section{TABLE OF CONTENTS}

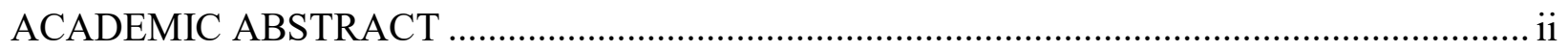

GENERAL ABSTRACT ………………………………....................................................

ACKNOWLEDGEMENTS ...........................................................................................

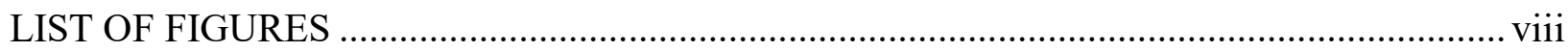

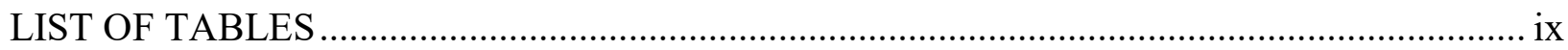

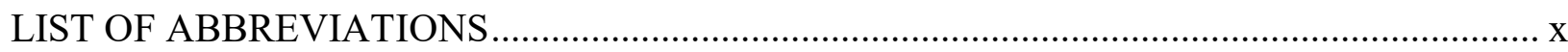

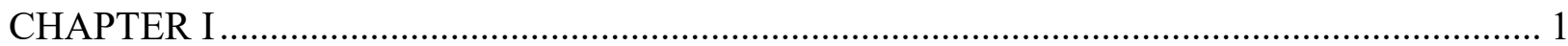

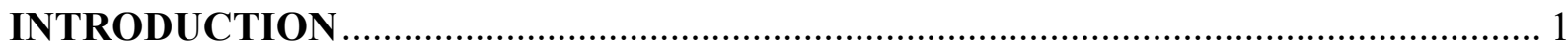

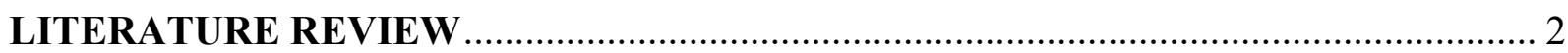

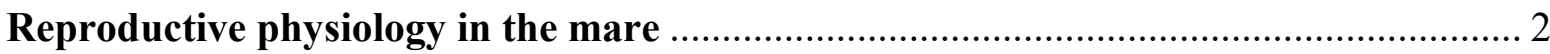

Hormonal profile in pregnant and non-pregnant mares ............................................. 3

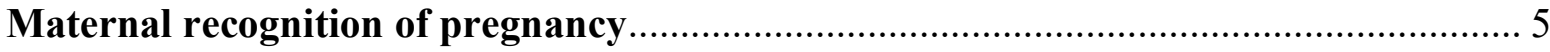

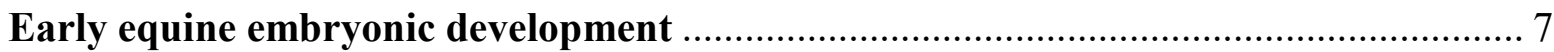

Trophectoderm and induced trophectoderm (iTr)................................................... 10

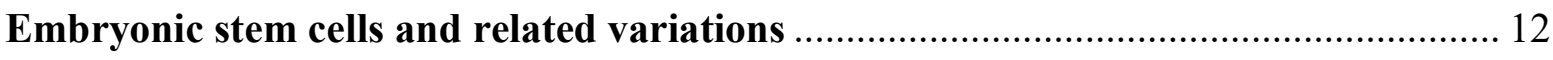

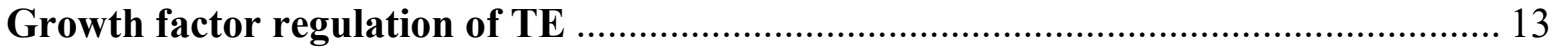

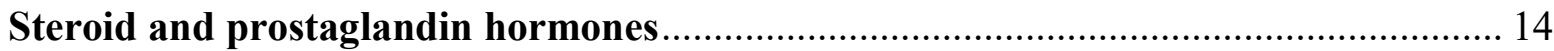

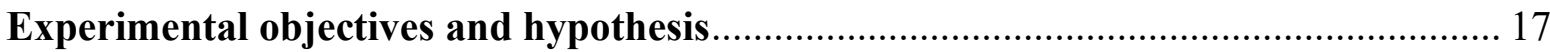

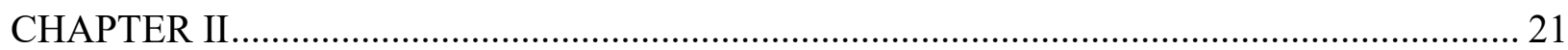

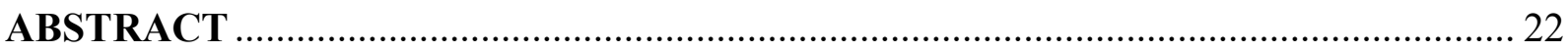

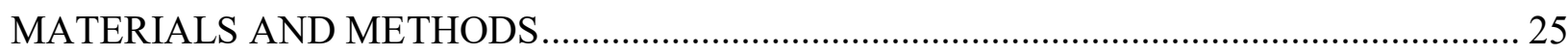

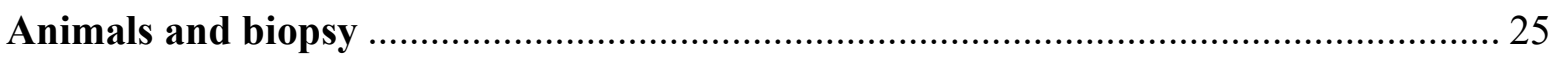

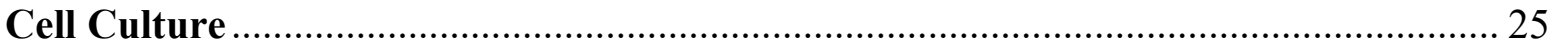

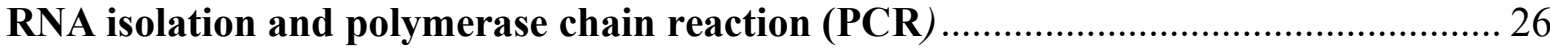

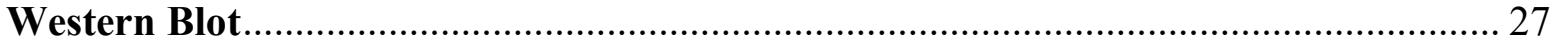

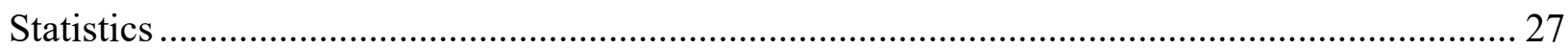

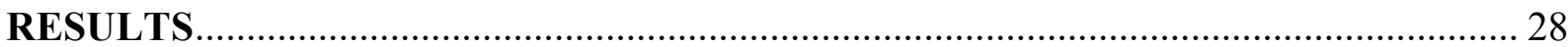

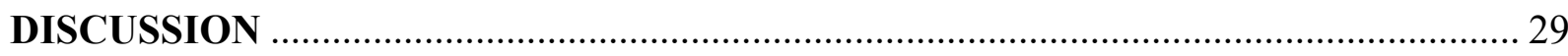

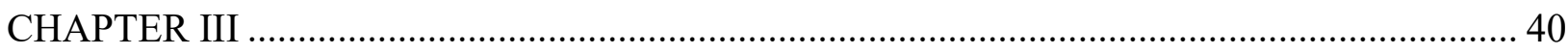

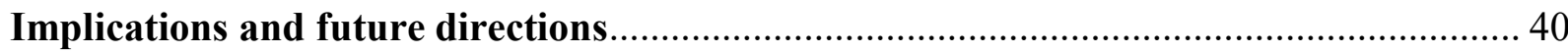

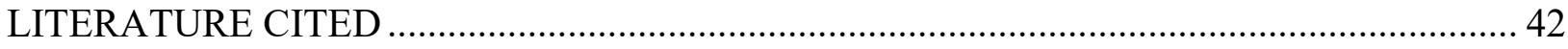




\section{LIST OF FIGURES}

Figure 1-1. The estrous cycle of the mare (Adapted from (Brinsko et al., 2010)..................... 18

Figure 1-2. Simplified scheme of the classic steroid biosynthetic pathway (Adapted from (Hofland et al., 2010))....................................................................................................... 19

Figure 1-3. Cellular pathways of prostaglandin (PG) metabolism (Adapted from (Phillips et al.,

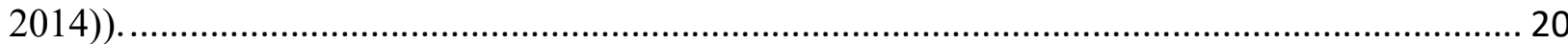

Figure 2-1. Expression of potential embryokines in equine liver, endometrium and iTr cells.... 33

Figure 2-2. Phosphorylation of AKT1 and ERK1/2 in response to selected growth factors ....... 34

Figure 2-3. Equine iTr cells proliferate in response to EGF, HGF and IGF-1 in an AKT1dependent manner.

Figure 2-4. Equine iTr cells require MEK/ERK signals for proliferation. 36

Figure 2-5. Growth factor treatment of equine iTr cells differentially affects steroidogenic gene expression 


\section{LIST OF TABLES}

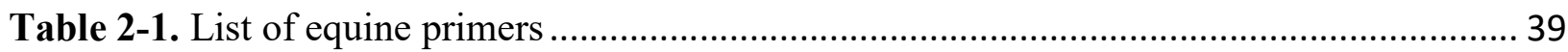




\section{LIST OF ABBREVIATIONS}

AP, Alkaline phosphatase

CDX2, caudal type homeo box transcription factor 2

CL, corpus luteum

c-MET, hepatocyte growth factor receptor

CYP11A1, cholesterol side-chain cleavage enzyme

eCG, equine chorionic gonadotropin

EGF, epidermal growth factor

EOMES, eomesodermin

ESC, embryonic stem cells

ESR, estrogen receptor

FBS, fetal bovine serum

FGF, fibroblast growth factor

GAPDH, glyceraldehyde 3-phosphate dehydrogenase

GATA, GATA-binding protein

GALNT1, polypeptide N-acetylgalactosaminyltransferase

HAND1, heart and neural crest derivatives-expressed protein 1

HSD3, 3Beta Hydroxysteroid dehydrogenase

ICM, inner cell mass

IGF, insulin-like growth factor

iPSC, Induced pluripotent stem

ISG15, interferon-stimulated gene 15

iTr, induced trophoblast

LIF, leukemia inhibitory factor 
MAPK, mitogen activated protein kinase

MRP, maternal recognition of pregnancy

mTOR, mammalian target of rapamycin

MUC, mucin-coding

NEU, Neuraminidase

NANOG, Nanog homeobox

OCT4, octamer-binding transcription factor 4

$\mathrm{PGE}_{2}$, prostaglandin $\mathrm{E}_{2}$

PGF2 $\alpha$, prostaglandin F 2 alpha

PGFM, PGF2 $\alpha$ metabolite

PI3K, phosphatidylinositol 3-kinase

PO, post ovulation

PR, progesterone receptors

PTGS2, prostaglandin-endoperoxide synthase 2

RTK, receptors tyrosine kinase

SOX2, sex determining region Y-box 2

SPLA2, secretory Type II Phospholipase A2

STAR, Steroidogenic acute regulatory protein

TE, trophectoderm

TEAD4, transcriptional enhancer activator domain family member 4

TFAP2A, transcription factor activating protein 2-alpha

TGM3, transglutaminase 3

VEGF, vascular endothelial growth factor

ZP, zona pellucida 


\section{CHAPTER I}

\section{INTRODUCTION}

The Thoroughbred horse industry is driven by the production of foals with racing aspirations as two-years old. Every foal on the ground brings with it substantial financial investments as well as a concerted effort to rebreed the mare for the subsequent year. The average pregnancy rates with natural breeding is around 50-60\% per cycle (Scherzer, 2010). The cost of maintaining a mare every year, oscillates between US\$15,000 and US\$18,000 (personal communication) and these values are generally buffered with the incomes generated from the sale of a foal. Thus, a mare that does not get pregnant at the end of a breeding season reflects in a full year of costs without any financial income. As an example, the average selling price in 2016 of a Thoroughbred weanling in the US is U\$64,848 and in 2018 for yearling is U\$129,335. Since there is no guarantee of a pregnancy in the following season, barren mares create a significant burden to the equine industry.

To establish and successfully maintain a pregnancy, the mare's uterine environment undergoes a series of events in preparation to receive the embryo. The equine embryo migrates from the oviduct to the uterus around 6.5 days after fertilization, initiating a continuous process of interaction with the mare's uterus. The early embryo signals its presence in the uterus through diverse biochemical signaling processes that allow for the maintenance of a corpus luteum and interruption of the oestrous cycle (Klein, 2015). As a consequence, the secretion of prostaglandin F2- $\alpha$ (PGF2 $\alpha$ ) is delayed preventing the process of luteolysis, and thus prolonging the supply of progesterone required to maintain pregnancy (Klohonatz et al., 2015). This process is known as “maternal recognition of pregnancy" (MRP) (Short, 1969). The cells of the outer layer of the equine blastocyst drive the primary signaling events from the embryo to the mare's 
endometrium, resulting in embryo fixation, implantation and the development of the placenta. Despite a firm understanding of the global processes of pregnancy establishment and maintenance in the mare, there are important gaps in knowledge concerning the signaling molecules and mechanisms involved with MRP in horses.

Equine induced trophoblasts (iTr) cells display similar in vitro behavior as embryoderived trophoblasts, in addition to a highly overlapping transcriptome (Reinholt et al., 2017). Thus, iTr cells represent an invaluable tool to study trophectoderm mediated events involved with MRP. A better understanding of the factors underlying MRP can lead to advances in equine subfertility, and provide a basis for therapeutic approaches to pregnancy failure in horses.

The thesis tested the hypothesis that equine iTr cells proliferate in response to growth factors commonly found in the uterine milieu and these growth factors alter steroidogenic gene transcription.

\section{LITERATURE REVIEW}

\section{Reproductive physiology in the mare}

The mare is a seasonal breeder with estrus occurring during the long days of spring and summer. The mare is mainly monovulatory with an estrous cycle that lasts on average 21 to 22 days with a period of 5-7 days of estrus (Fig 1-1) (Aurich, 2011). Before each ovulation, high concentrations of estrogens and luteinizing hormone cause the mare to show behavioral signs of estrus. After the ovulation occurs, progesterone levels increase reaching a maximum concentration at day 8 post-ovulation (PO). If the mare is not pregnant at day 14 to $15 \mathrm{PO}$, the endometrium will produce PGF2 $\alpha$ leading to luteolysis and a decrease in progesterone levels. Within a few days after luteolysis, the mare will start a new estrous cycle (Brinsko et al., 2010) . If the mare is pregnant, the ovulatory CL will be the primary source of progesterone with 
secondary CLs providing additional progesterone. The placenta becomes the primary source of progesterone secretion at day 150-200 of gestation (Brinsko et al., 2010).

\section{Hormonal profile in pregnant and non-pregnant mares}

Pregnant and non-pregnant mares have a similar hormonal profile until d 14 PO (Klohonatz et al., 2015). In pregnant mares, progesterone and estrogen receptors (PR and ESR, respectively) are present in the uterine endometrium at day $10 \mathrm{PO}$ and decline in number between days 15 - 20 PO. In non-pregnant mares, $P R$ and $E S R$ expression are greater during estrus and late diestrus, preparing for the next cycle (McDowell et al., 1999).

Oxytocin $(\mathrm{OXT})$ in the mare is produced by the endometrium in contrast to other species, in which the endometrium secretes prostaglandin, but not OXT. The mare also has OXT receptors in the endometrium thus, creating an autocrine circuit (Aurich, 2011). Similar to other species, the mare uterine endometrium releases PGF2 $\alpha$ in response to OXT, producing a positive feedback loop that is important to luteolysis (Burns et al., 1997; Sharp et al., 1997). OXT and PGF2 $\alpha$ are released in pulses, but PGF2 $\alpha$ 's pulses are more discrete (Douglas and Ginther, 1976). During estrus and late diestrus, $O X T$ expression is greater than during other phases of the cycle (Behrendt-Adam et al., 1999). In agreement, mares injected with OXT during late diestrus were reported to exhibit a plasmatic increase PGF2 $\alpha$ metabolite (PGFM), the main metabolite of PGF2 $\alpha$ (Goff et al., 1987). Similarly, in vitro observations of endometrial explants treated with OXT, resulted in a rise in PGF2 $\alpha$ secretion (Ealy et al., 2010). On the other hand, OXT administration at or before day 8 PO does not induce luteolysis, suggesting that the OXTdependent luteolytic mechanisms are not established until late diestrus (Neely et al., 1979), being the endometrium only responsive to OXT secretion at or after day 11 PO (Goff et al., 1987). 
The effects of OXT and PGF2 $\alpha$ are different between pregnant and non-pregnant mares. In early pregnancy, mares show a limited ability to secrete PGF2 $\alpha$ in response to OXT. However, in non-pregnant mares, OXT is produced by the endometrium and pituitary gland, resulting in a greater production of OXT and PGF2 $\alpha$. Consequently, luteolysis of the CL will occur inducing the mare to cycle again (Sharp et al., 1997). Compared to pregnant mares, the non-pregnant mare's endometrium expresses greater amounts of prostaglandin-endoperoxide synthase 2 (PTGS2) and secretory Type II Phospholipase A2 (SPLA2 also known as PLA2G2A) mRNA, both enzymes involved in prostaglandin synthesis (Klohonatz et al., 2015).

A study evaluating uterine flush content, found that at day 14-16 PO pregnant mares contain less PGF2 $\alpha$ than cycling mares (Berglund et al., 1982). Uterine flushes done after day 18 of pregnancy contain concentrations of PGF2 $\alpha$ similar to cyclic mares undergoing luteolysis, suggesting that the equine embryo doesn't prevent PGF2 $\alpha$ secretion during pregnancy, but delays it (Stout and Allen, 2002). In vitro exposure of endometrial explants to embryo secretions decreased PTGS2 expression while those exposed to OXT had increased PTGS2 expression. This indicates that during early pregnancy the equine embryo could be targeting the enzyme as an antiluteolytic signal (Ealy et al., 2010).

At day 25 of pregnancy, part of the trophoblast goes through cellular changes and form the chorionic girdle. Around day 38 of pregnancy, these trophoblastic cells of the chorionic girdle invade the uterine epithelium forming the endometrial cups. The endometrial cups secrete equine chorionic gonadotropin (eCG). This hormone is first detectable in the maternal blood around day 35-42 and around day 100-150 is undetectable. The role of this hormone is to assist the supplementary CL formation and stimulates the maintenance of the primary CL. In addition, it plays a key role in immunoregulation during the pregnancy (Brinsko et al., 2010) 


\section{Maternal recognition of pregnancy}

The window during which maternal-fetal recognition occurs is unclear. However, the embryo-derived signal should be present before 14 PO in order to prevent PGF2 $\alpha$ secretion from the endometrium, resulting in the lysis of the corresponding CL (Boerboom et al., 2004). Dialysis of conditioned media from equine embryos at day 14 PO co-cultured with endometrial explants from mares at the same length of gestation, identified a protein of molecular weight within the 1 to $6 \mathrm{kDa}$ range (Sharp et al., 1989). Another study, using equine embryos at day 13.5 PO, treated with either proteinase K or dextran-coated charcoal, identified a proposed MRP signal (s) of molecular weight within the 3-10 kDa range (Ababneh et al., 2000). These studies indicate that the trophectoderm of the embryo synthesizes and releases a protein molecule during the MRP timeframe that can suppress PGF2a secretion.

The phenomenon of MRP has been studied in several different species for the past 50 years. Several pathways involved in MRP have been discovered providing a detailed understanding of this process in cattle, sheep and pigs (Klein, 2015). The elongation of the trophoblast through the uterus in ruminants and pigs allows the materno-fetal interaction that is key for the implantation and placentation (Geisert et al., 1990). In the pig between day 10 and 14 PO, the spherical embryo elongates and the trophoblast cells start to produce and release estrogens that interfere with the normal secretion of endometrial PGF2 $\alpha$. The embryo-derived estrogens are able to redirect endometrial PGF2 $\alpha$ secretion away from the uterine vein (endocrine secretion) to the uterine lumen (exocrine secretion). By extrapolation, several studies evaluated the effects of estradiol administration on luteolysis in the mare. Uterine infusions with estradiol were performed in non-pregnant mares from day 10 to day 16 PO. Nonetheless, the lifespan of the CL was not different from sham-treated mares suggesting that the hormone does 
not delay luteolysis (Vanderwall et al., 1994). Systemic injections of different concentrations of exogenous estradiol over the course of an estrous cycle (or up to 32 days maximum) also failed to prevent CL regression (Woodley et al., 1979). Experiments introducing estradiol impregnated spheres to mare's uteruses were performed (Goff et al., 1993), though none of the treatments managed to delay luteolysis, with mares returning to cyclicity (Woodley et al., 1979). Daily supplementation of diethylstilbestrol from day 7 though day 18 PO (Berg and Ginther, 1978), prolonged the CL lifespan and suppressed a new wave of follicular growth. Diethylstilbestrol is a synthetic estrogen and thus this response does not mimic the physiological context. More recent studies, performed uterine infusions with different types of oils and estradiol at different days PO. The only mixture that prolonged the lifespan of the CL in mares was a combination of coconut oil and estradiol administered at day 6 PO. Based on these results, the authors concluded that this vegetable oil could be involved in prostaglandins synthesis in the mare's endometrium leading to delayed luteolysis (Wilsher and Allen, 2011). Since all these experiments were performed in non-pregnant mares, it can't be ruled out that the embryo-derived estrogen could be involved in MRP.

Interferon tau is the MRP factor in ruminants. The establishment of a pregnancy involves the suppression of the endometrial secretions of PGF2 $\alpha$ in order to maintain the CL secretion of progesterone. The trophoblast produces interferon tau around day 10-16 PO, inhibiting the endometrial receptors for OXT thereby disrupting the uterine secretion of PGF2 $\alpha$ and maintaining the pregnancy (Bazer et al., 1997).

Equine embryos express two interferon delta genes, EqIFN-delta 1 and EqIFN-delta, during early pregnancy at day 16 and day 22 (Cochet et al., 2009). Different types of interferons were measured in equine embryos at day 13, 15,20 and 25 of pregnancy. The results indicated 
that equine embryos were unable to produce interferon-like protein molecules that can avoid luteolysis (Baker et al., 1991). In horse has been observed that interferon-stimulated gene 15 (ISG15) is present in the mare's endometrium during early pregnancy and at the time of embryonic implantation. However, the expression of ISG15 was not different between nonpregnant and pregnant mares at day 14 and 50 PO leading the authors to conclude that ISG15 is probably involved in cellular functions unrelated to MRP. In summary, there is no evidence that interferon molecules are modulators of MRP in the mare (Klein et al., 2011).

Prostaglandin $\mathrm{E}_{2}\left(\mathrm{PGE}_{2}\right)$ is part of the prostaglandin hormone family. It is associated with the process of luteolysis in pigs and ruminants. During pregnancy, gilts and ewes, have an increase in intrauterine $\mathrm{PGE}_{2}$ concentrations. Uterine infusions with $\mathrm{PGE}_{2}$ delays the process of luteolysis in both swine and sheep (Pratt et al., 1977; Christenson et al., 1994). In a similar manner, equine embryos produce $\mathrm{PGE}_{2}$ as early as 5 days $\mathrm{PO}$ until at least day $15 \mathrm{PO}$, doubling the amount between day 13 and 15 of pregnancy (Weber et al., 1991). $\mathrm{PGE}_{2}$ receptors are present in the mare's endometrium, making it a perfect target for the $\mathrm{PGE}_{2}$ secreted by the embryo (Weber et al., 1992). Additionally, several cases with unexplained fertility problems have resolved with a $\mathrm{PGE}_{2}$ injection into the serosa of the oviduct (Arnold and Love, 2013). Uterine infusion of $\mathrm{PGE}_{2}$ in non-pregnant mares showed an increase in CL lifespan compared with control and sham treatment suggesting that $\mathrm{PGE}_{2}$ secreted from the embryo is related with prolonging CL lifespan in pregnant mares (Vanderwall et al., 1994).

\section{Early equine embryonic development}

Embryonic development in mammals is characterized by the early differentiation of trophoblast lineage, which is in charge of providing means by which the embryo, and further the fetus, survive in the uterus (Pfeffer and Pearton, 2012). After the morula is formed it divides in 
two very different and special structures reaching the stage of blastocyst. The trophectoderm (TE) that further gives origin to the placental tissues, and the inner cell mass (ICM) that contributes to form the fetus itself. The TE, is the first extra-embryonic tissue that forms the outer cell layer of the blastocyst (Iqbal et al., 2014). The TE originates all the trophoblast cells lineage that later will form part of the placenta and the periphery of the embryo (Gardner and Beddington, 1988; Rossant, 2007), and plays a key role in embryonic implantation (Pfeffer and Pearton, 2012). The ICM, also differentiates into two structures, the hypoblast and epiblast. Hypoblast or primitive endoderm, like the TE, gives rise to extra-embryonic tissues such as the visceral yolk sac and parietal endoderm. On the other hand, the epiblast or primitive ectoderm, is a structure that lies above the hypoblast, and generates the allantois, amnion, extra-embryonic mesoderm of the visceral yolk sac and the three primary layers (endoderm, mesoderm and ectoderm) (Gardner and Beddington, 1988).

The mare's oviduct is very selective with regards to cell transit through its lumen. Around 6.5 days PO, fertilized ova are able to pass the through oviduct into the uterus due in part to $\mathrm{PGE}_{2}$ directed oviduct dilatation (Weber et al., 1991). When the embryo reaches the uterus, it is still surrounded by the zona pellucida (ZP) with a thick acellular glycoprotein membrane immediately beneath it and atop the trophectoderm (Betteridge et al., 1982; Battut et al., 1997; Betteridge, 2007). As the ZP starts to get thinner, the embryo is able to expand in size and the $\mathrm{ZP}$ is shed. The capsule is then the only surrounding protection for the embryo. The capsule is a unique structure amongst domestic animals, and provides mechanical resistance to uterine contractions that propels the embryo during the mobility phase (Oriol et al., 1993). Artificial removal of the capsule from embryos at day 6-7 PO demonstrated their inability to survive after transfer into recipient mares reinforcing its role in promoting early embryo protection and 
survival (Stout et al., 2005). The capsule is composed by mucin-like glycoproteins produced by the trophoblast (Albihn et al., 2003). The embryo expresses sialyltransferases and sialic acid transporters, which builds the carbohydrate content of the capsule glycoproteins. Sialic acid content is greatest during day 8-14 PO and this seems to be related to an antiadhesive function (Klein and Troedsson, 2011a). The sialic acid content within the capsule decreases around day 16-17 PO, coinciding with embryonic fixation (Arar et al., 2007). Neuraminidase 2 (NEU2), is an enzyme expressed by the embryo, is responsible for removing the sialic acid from glycoproteins suggesting that the embryo regulates the content of sialic acid of its own capsule (Klein and Troedsson, 2012). The capsule is absent at day 21-23 PO (Betteridge, 2007). Mucincoding genes (MUC1 and 2), genes involved in proteoglycan synthesis (GALNT1,4 and 12) are also transcribed by the TE and important for capsule formation (Iqbal et al., 2014). Although it has been demonstrated that the trophoblast cells produce capsule material, researchers are unable to reproduce this phenomenon suggesting that the equine embryo needs the endometrial microenvironment to accomplish the task. Permeation of capsule material through membrane channels, probably due to poor binding of the glycoprotein to the trophectodermal surface, also contributes to the failed capsule formation in vitro (Tremoleda et al., 2003). The embryo doesn't need the ZP in order to form the capsule because bisected blastocysts form a capsule after transfer into recipient mares (McKinnon et al., 1989).

Unlike ruminants or pigs that elongated their trophoblast in order to interact with the endometrium, equine embryo mobility throughout the uterus is a remarkable feature among domestic animals, and was documented by ultrasound beginning at day 9 PO with peak movement during 11-15 PO (Ginther, 1983). At day 16 PO, the embryo's size limits its movements through the uterus, as well as an increase in uterine tone (Gastal et al., 1996). The 
embryo is propelled through the uterus by myometrial contractions stimulated by the embryo secretion of prostaglandin E2 and F2a (Watson and Sertich, 1989; Weber et al., 1991). Embryo mobility is reduced in pregnant mares treated with flunixin meglumine (a prostaglandin inhibitor) from day 10 to 18 of pregnancy. Restricting embryo mobility to only one horn during 10-18 days PO increases endometrial secretion of PGF2 $\alpha$ and terminates the pregnancy. The embryo needs to be in contact with at least $2 / 3$ of the endometrium to avoid luteolysis and maintain the pregnancy, demonstrating that movement is vital for equine MRP (McDowell et al., 1988).

\section{Trophectoderm and induced trophectoderm (iTr)}

Trophectoderm cells are the precursors of the primitive placenta in eutherian mammalian. These cells are crucial mediators in the survival and growth of embryos (Rielland et al., 2008). Any type of disruption in the trophoblast can cause problems embryonic or fetal development (Godfrey, 2002). Even though placentas from different species can have some functional and structural similarities, there is a big molecular diversity among species, generating a wide set of targets of research interest (Douglas et al., 2009).

Transcription factors including TEAD4, GATA3, OCT4, CDX2 (Iqbal et al., 2014) and EOMES are present in the equine TE (Iqbal et al., 2014; Reinholt et al., 2017). CDX2 and EOMES are the main transcription factors during the early TE development in mice. Bovine TE does not express EOMES indicating specie differences (Russ et al., 2000). CDX2 is one of the first trophoblast-specific genes to be expressed and it is indispensable for the trophoblast lineage formation and the TE function. Mice embryos genetically ablated of CDX2 are unable to implant (Strumpf et al., 2005). TEAD4 is required in mice for CDX2 expression (Ralston et al., 2010). By contrast, EOMES is important for differentiation and proliferation of the TE after the 
blastocyst expands (Strumpf et al., 2005). EOMES null mice demonstrate arrested blastocyst development prior to implantation. Suggesting that EOMES is required for the differentiation of the trophectoderm into the trophoblast (Russ et al., 2000).

The GATA transcription factor family is involved in the regulation of mammalian embryo development. Two of the family members, GATA2 and GATA3, are expressed in both the human and mouse trophoblast lineage. A study showed that GATA2/GATA3 knockout mouse embryos were unable to mature to the blastocyst stage due to an abnormal TE growth (Paul and Home, 2015). They also demonstrated that GATA2/GATA3 are crucial for the trophoblast lineage and to regulate and maintain balance the maternal-fetal interface. In mice, GATA3 ablation reduces CDX2 expression (Home et al., 2009) and in cattle, CDX2 expression is increased when GATA2 is overexpressed (Bai et al., 2012).

A hallmark of trophoblast differentiation is the formation of giant cells, also called binucleated cells. These cells are involved in the maternal-fetal union and in the synthesis of hormones and proteins required to maintain a pregnancy (Hu and Cross, 2010). GCM1 and HAND1 play a critical role stimulating giant cells differentiation (Scott et al., 2000), and in the horse they are expressed between 21-25 days PO, when CDX2 expression is decreasing (de Mestre et al., 2009).

A novel equine TE cell line (iTr) that closely mimics the genotype and phenotype of native equine TE, was recently created (Reinholt et al., 2017). This cell line has an epithelial-like morphology with a flat cobblestone appearance that are capable of forming dome-shaped structures (Saito et al., 2002). When cultured in suspension, iTr form hollow spheres that are very similar to an equine day 8 embryo. The transcriptome of equine iTr displays identical core TE lineage markers when compared to that of native TE cells from $\mathrm{d} 8$ embryos as revealed by 
RNA-sequencing. Both express EOMES, TFAP2A, TEAD4, CDX2, GATA2 and POU5F1

(OCT4) (Reinholt et al., 2017) A similar cell line was created through incomplete reprogramming of porcine mesenchymal stem cells. Porcine iTr cells spontaneously form floating spheres when confluent, and can form non-hemorrhagic teratomas. The iTr cells express several TE markers with few pluripotency genes (Ezashi et al., 2011).

\section{Embryonic stem cells and related variations}

Cells derived from the ICM, known as embryonic stem cells (ESC), are pluripotent and capable of self-renewal, differentiating into cells of all germ layer (Desmarais et al., 2011). They express the pluripotency markers (OCT4, SOX2 and NANOG) (Han et al., 2011). Studies done in equine embryos from days 8 to 14 PO showed that NANOG is present in the ICM but not in the TE (Iqbal et al., 2014). Immunosurgical dissection of ICM cells of day 8 blastocysts could be passaged up to 28 times and expressed OCT4, FUT4, AP, TRA-1-81, TRA-1-60, a defined panel of ESC markers. However, once these cells were injected in mouse, teratoma(s) failed to develop (Li et al., 2006)

The fibroblast growth factor (FGF) family is involved in signaling pathways also present in the ICM. In human embryonic stem cells, FGF2 signaling favors their pluripotency and selfrenewal (Diecke et al., 2008). Expression of FGF2 and its receptors (FGFR1, FGFR4 and GAB1) is higher in the equine ICM than TE cells (Iqbal et al., 2014). During blastocyst development, FGF signaling is crucial for the differentiation process from ICM to epiblast (Yamanaka et al., 2010). The generation of embryonic stem cells from the ICM in the horse have had several attempts, but all have failed because ICM derived cells transform into TE. Therefore, it is suggested that the unsuccessful transformation to horse ES cells could be because of the high FGF pathway activity in the ICM of the horse (Iqbal et al., 2014). 


\section{Growth factor regulation of TE}

To gain more information about gene expression in equine iTr cells, Reinholt et al (2017) conducted a bioinformatics study of the iTr transcriptome. The analysis revealed many ligand and receptors tyrosine kinase (RTK). Several growth factors' receptors signal to different biological responses through mitogen activated protein kinase (MAPK) and phosphatidylinositol 3-kinase (PI3K). The receptors for platelet derived growth factor family was highly expressed in the transcripts, including the hepatocyte growth factor receptor (c-MET), EGF and FGF receptors 1, 3 and 4. Also, IGF-1 and -2 ligand and receptors were present, indicating an autocrine signal (Reinholt et al., 2017).

In the mouse, c-MET is the mediator of the allantoic mesenchyme and trophoblast interaction, inducing proliferation and differentiation (Stewart, 1996). Homozygous c-MET mutant (-/-) mouse embryos that died before day 16.5 of pregnancy, showed developmental defects in the placenta, damage of liver parenchyma, a smaller liver and poor skeletal muscle development, bringing evidence that, at least in mice, c-MET is crucial for embryonic and placental development (Bladt et al., 1995). The function of c-MET in the equine trophectoderm remains unknown (Stewart, 1996).

IGF-1 and their receptors participate in mammalian embryonic and fetal development (Klein et al., 2010). The blastocoel cavity is an important source of IGF-1 (Walters et al., 2001). Both the embryo and uterine endometrium express IGF-1 in an estrogen-independent manner, unlike swine (Walters et al., 2001). IGFBP1 is highly expressed in the pregnant mare's uterus (Klein et al., 2010). Researchers suggested than IGFBP1 may regulate the transportation of IGFs between the uterine lumen and endometrium of the pregnant mare (Klein et al., 2010). EGF from 
the maternal endometrial gland, is in charge of originating and maintaining the tissues growing and remodeling the feto-maternal interface in both sides in the horse (Allen and Stewart, 2002).

Equine iTr cells express FGF2 receptors 1,3 and 4 but not the corresponding ligand, indicating the absence of and autocrine loop (Reinholt et al., 2017). Interestingly, equine iTr cells expressed FGF7 ligand but not its receptor FGFR2b, however its role has not yet been described in the horse. In humans, FGF7 promotes cytotrophoblasts differentiation towards synctiotrophoblasts (Massabbal et al., 2005). In pigs, during early pregnancy, FGF7 receptor and ligand are expressed in the endometrial epithelia. The receptor is also expressed by the TE, suggesting a possible paracrine interaction between the embryo and the endometrium (Ka et al., 2000). A study done in horses showed that FGF2 was present in the equine embryo and its mRNA expression decreased throughout the embryo development (Klein and Troedsson, 2011b). In bovine embryos, close to the elongation, FGF2 increases in expression (Cooke et al., 2009). Although FGF2 was not present in the equine iTrs' transcriptome, expression of the corresponding receptors (FGFR1,3,4) was, suggesting that in this species, the endometrium may be the source of the ligand (Reinholt et al., 2017).

\section{Steroid and prostaglandin hormones}

In several species, hormones like prostaglandin, progestin and estrogens play a central role in the establishment of pregnancy (DeFranco, 2002).

Estrogen and its receptors play an important role in luteolysis in ruminants, upregulating OXT receptors in the endometrium. Oxytocin binds to its receptors and initiates PGF2 $\alpha$ pulsatile secretion (Bazer et al., 1986). In the early gestational ewe, ESR1 is inhibited by IFNT which blocks OXT receptors inhibiting luteolysis (Spencer and Bazer, 1995). In cyclic mares, OXT plays a main role in luteolysis, increasing the endometrial secretion of PGF2 $\alpha$. ESR1 might be 
involved in the induction of luteolysis in a similar way than in ruminants however, the mechanism of action has not been documented (Klein et al., 2010). Variations in ESR1 expression during the estrous cycle have been shown in different species. For example, in pregnant ewes, ESR1 is lower during early pregnancy (day 11 to 14 ) increasing between day 15 to 25. Non-pregnant ewe express high levels of ESR1 as early as at day 1 and between 11-15, and it is lower between day 1-6 when progesterone is higher (Spencer and Bazer, 1995). In cycling mares, expression ESR1 and progesterone receptors is higher during estrus and lower during mid/late diestrus (between days 11-14) while in pregnant mares it is lower during early pregnancy (up to day 20 PO) (Hartt et al., 2005). A study performed by Klein et al also identified that ESR1 expression was lower at day 13.5 PO in pregnant mares than in non-pregnant mares. Therefore, the low expression of ESR1 in pregnant mares could be related to low OXT, no PGF2 $\alpha$ secretion resulting in inhibition of luteolysis (Klein et al., 2010).

Equine embryos also express enzymes involved in steroid hormones synthesis (Fig 1-2). Steroidogenic acute regulatory protein (STAR), is a transport protein which regulates the cholesterol transport in the mitochondria, a rate limiting step for the production of steroid hormones. In the sow, STAR is the main regulator of steroidogenesis (Blomberg and Zuelke, 2005). This enzyme is highly expressed in equine embryos day 12-14 PO compared to day 8 embryos (Klein and Troedsson, 2011b), but was not present in the iTr transcriptome.

The cholesterol side-chain cleavage enzyme (CYP11A1), is the rate limiting enzyme involved in steroidogenesis and converts cholesterol into pregnenolone (Tu et al., 2014). This enzyme is expressed by the horse embryo (Klein, 2015) and the iTr cells (Reinholt et al., 2017). CYP17A1 and CYP19A1, a cytochrome P450 enzyme and an aromatase respectively, start increasing their expression in the equine embryo at day $12 \mathrm{PO}$ and both are present in iTr cells. 
3Beta Hydroxysteroid dehydrogenase (HSD3), is also present in equine embryos and iTr cells. This enzyme is very important in the production of hormonal steroids of all classes. Its expression increases in embryos by day 12-14 PO (Klein and Troedsson, 2011b). CYP11A1, CYP19A1 and HSD3B1 haven't been found to be expressed in endometrial samples (Klein, 2015). Suggesting that the embryo is involved in steroidogenesis around the time range of MRP.

Rate limiting enzymes of the PLA2 family, such as SPLA2 (also known as PLA2G2A) and PLA2G4A (cPLA2) are required for prostaglandin synthesis (Fig 1-3) (Murakami et al., 1998). The arachidonic acid coming from the phospholipid bilayer is cleaved by SPLA2 and mobilized by PLA2G4A (Klohonatz et al., 2015).

PLA2G4A regulates the secretion of PGF2 $\alpha$ and its expression increase in the mare endometrium close to luteolysis. PLA2G4A expression is higher during estrus and lower but maintained steady around day 8 PO. There is no difference between pregnant and non-pregnant mares with high P4 at day 15, but is lower than non-pregnant mare with low P4 (Ababneh et al., 2011). SPLA2 has been involved in degradation of the embryo's capsule. During early pregnancy, increase in SPLA2 after PGF2 $\alpha$ administration blocks embryo fixation with resulting in early loss of the pregnancy (Hayes et al., 2008). SPLA2 is not expressed in the $\mathrm{iTr}$ transcriptome, but PTGS2 and PLA2G4A are. The latest is also present in the equine embryo (Simpson et al., 1999).

Apolipoproteins are proteins which bind to lipids to form lipoproteins for transport. APOB, one of the 5 apolipoproteins, plays a main role in the mouse embryos growth. Via the yolk sac, APOB transports lipid nutrients to the mouse embryo, regulating the synthesis of lipoproteins. A study of horse embryos showed that apolipoproteins are up-regulated. These are involved in cholesterol transport and are present in the equine embryo. The authors suggested 
that apolipoproteins could have a similar function in the horse embryo than in mice, by providing nutrients for the embryo development (Klein and Troedsson, 2011a). Klohonatz et al compared the increase in apolipoproteins in embryos (day 8, 10, 12 and 14 PO) with a decreased in SPLA2 in endometrial samples from pregnant mares (day 12, 14, 16 and 18 PO) around the same time of embryo development, suggesting that the embryo could be controlling its own cholesterol transport (Klohonatz et al., 2015).

\section{Experimental objectives and hypothesis}

Given the absence of a defined MRP for the horse, the objective of the study was to examine the role of EGF, FGF2, HGF and IGF-1 on equine iTr cells. Our hypothesis was that iTr, similar to TE, demonstrate altered transcription of steroidogenic genes and growth kinetics in response to growth factors. Understanding the impact of growth factors on equine TE may lead to further insight into MRP in the horse. 


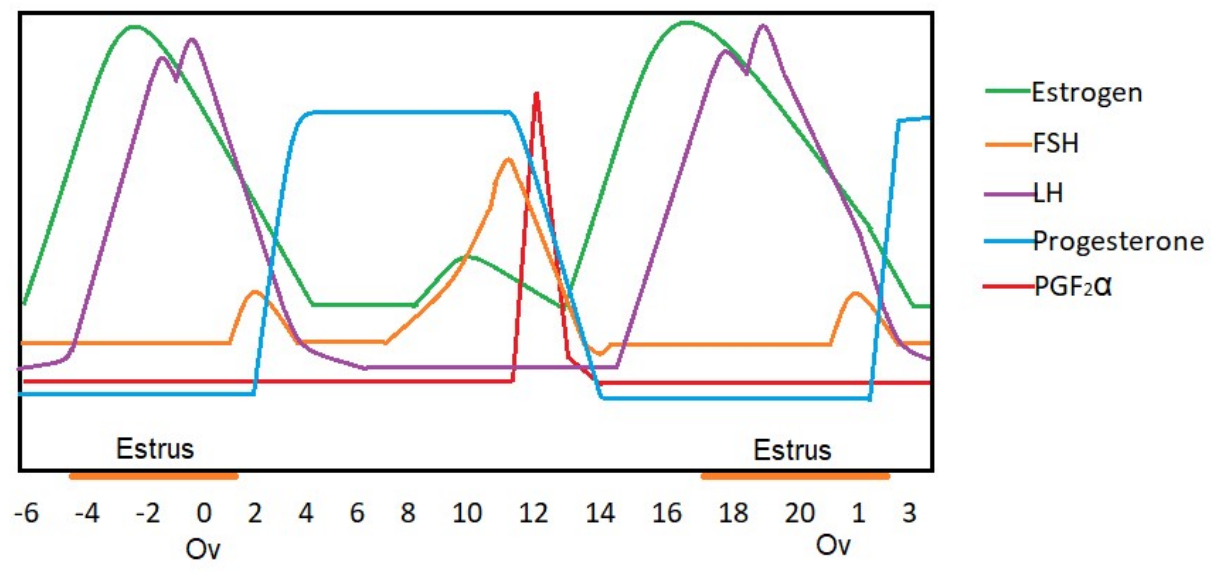

Figure 1-1. The estrous cycle of the mare (Adapted from (Brinsko et al., 2010). 


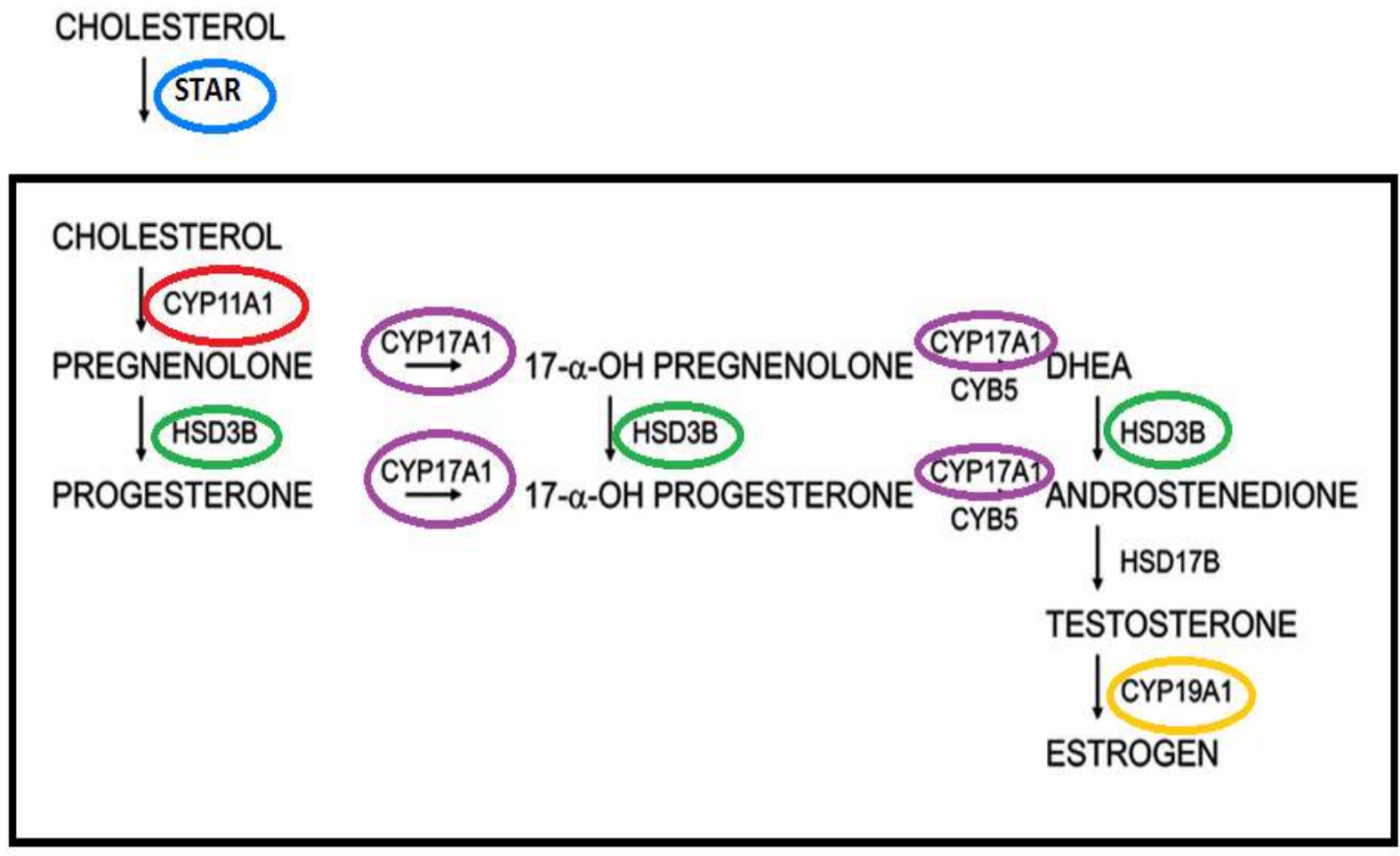

Figure 1-2. Simplified scheme of the classic steroid biosynthetic pathway (Adapted from (Hofland et al., 2010)). 


\section{Glycerophospholipids}
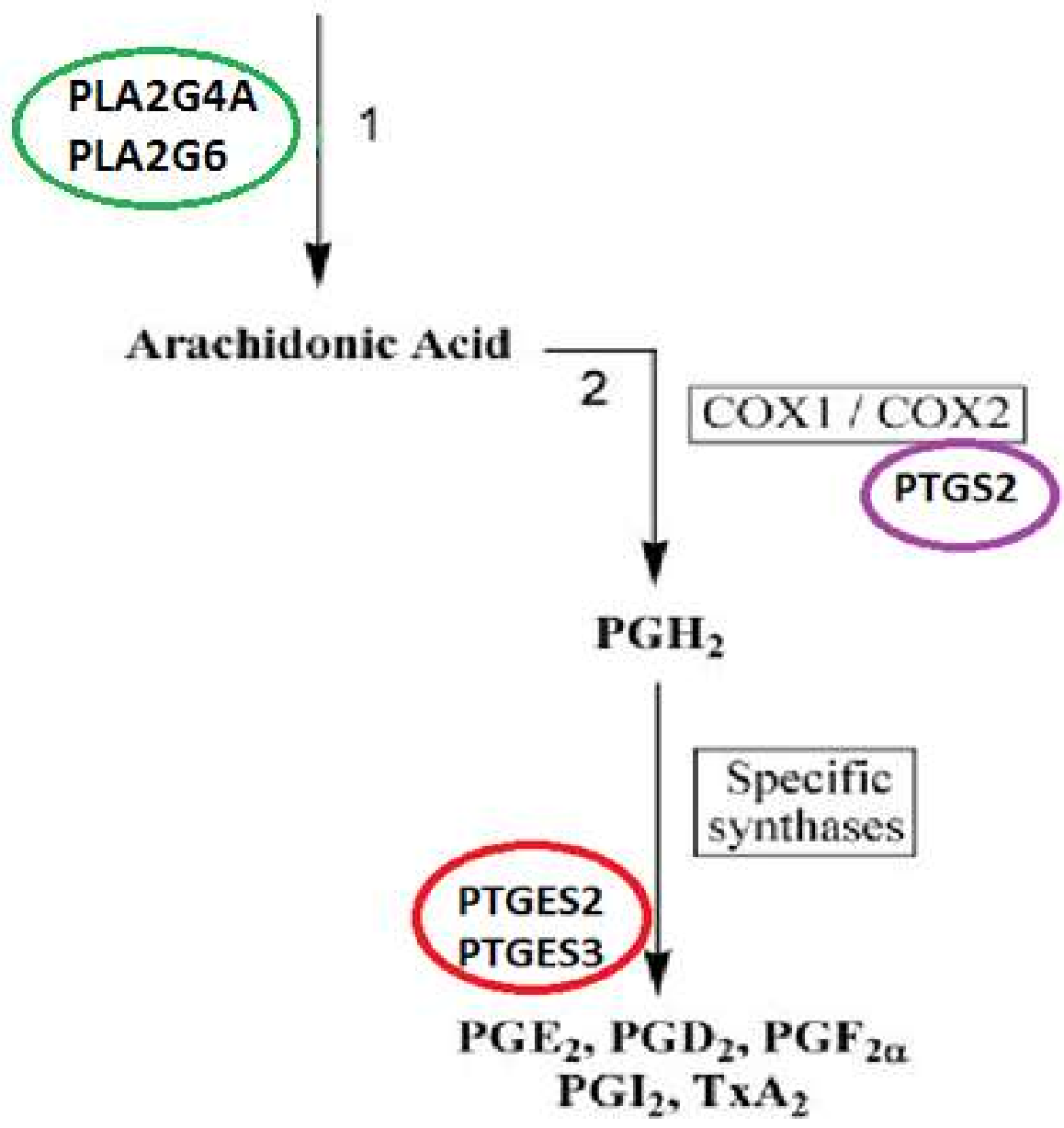

Figure 1-3. Cellular pathways of prostaglandin (PG) metabolism (Adapted from (Phillips et al., 2014)). 


\section{CHAPTER II}

Growth factor modulation of equine trophoblast mitosis and prostaglandin gene expression.

Susana Bonometti ${ }^{*}$ Bruno Carvalho Menarim ${ }^{\dagger}$, Brad M. Reinholt, Alan D. Ealy ${ }^{*}$ and Sally E. Johnson*

${ }^{*}$ Department of Animal and Poultry Sciences and ${ }^{\dagger}$ Department of Large Animal Clinical Sciences, Virginia Polytechnic Institute and State University, Blacksburg, VA 24061

Running title: Growth factors and trophoblast proliferation 


\section{ABSTRACT}

To provide insight into maternal recognition of pregnancy control in equids, the mitogenic and developmental effects of endometrium-expressed growth factors (epidermal growth factor (EGF), insulin-like growth factor 1 (IGF-1), fibroblast growth factor 2 (FGF2) and hepatocyte growth factor (HGF), were examined in equine iTr cells, an equine trophectoderm cell line. Initial Western blots revealed that HGF and IGF-1 stimulate phosphorylation of AKT serine/threonine kinase 1 (AKT1) and EGF, FGF2 or HGF resulted in phosphorylation of both extracellular signal-regulated kinase $1($ ERK1) and ERK2. Mitotic activity was stimulated $(P<$ 0.05) by EGF, FGF2 and HGF. Chemical disruption of mitogen activated protein kinase 1 and 2 $(\mathrm{MEK} 1 / 2)$ phosphorylation suppresses $(P<0.05)$ proliferation in control and growth factor treated cells demonstrating a dependence on ERK1/2 for mitotic activity. Treatment of iTr cells with EGF or HGF in the presence of an AKT1 inhibitor prohibits $(P<0.05)$ growth factor stimulated proliferation. The effect of EGF, FGF2, HGF and IGF-1 on steroid biosynthetic enzyme gene expression, including prostaglandin-endoperoxide synthase 2 (PTGS2), was determined by real-time PCR. Neither EGF, FGF2 nor IGF-1 affected PTGS2 expression while HGF caused a two-fold increase $(P<0.05)$ in expression. Co-supplementation with HGF and an AKT1 inhibitor did not block PTGS2 expression whereas providing a MEK1/2 inhibitor prevented $(P<0.05)$ the HGF-mediated increase in $P T G S 2$. These results provide novel evidence of a role for HGF in equine trophectoderm proliferation and prostaglandin biosynthesis.

KEY WORDS: hepatocyte growth factor, proliferation, prostaglandin, trophectoderm 


\section{INTRODUCTION}

Early embryogenesis in the horse is unique amongst domestic animals. Following fertilization of the ovum, the embryo travels through the oviduct and enters the uterus at 6 days post-ovulation whereas non-fertilized ova are not expelled into the uterus (Betteridge et al., 1982). Soon thereafter the blastocyst is surrounded by a thickened glycocalyx capsule that protects the embryo as it moves throughout the uterus because of intrauterine contractions that are mediated by prostaglandins $\mathrm{E}$ and $\mathrm{F}$, a requirement for establishment of pregnancy (McDowell et al., 1988; Stout and Allen, 2001). By day 10 of development, an embryonic disc is present, and gastrulation is complete by day 14 to 16 , when fixation within an uterine horn occurs (Gaivão et al., 2014; Klein, 2015).

Both capsule formation and uterine mobility are hallmarks of equid pregnancy establishment, but the underlying mechanism(s) of equine maternal recognition of pregnancy (MRP) remain largely unresolved. What is known is that manipulation of prostaglandin F2 $\alpha$ (PGF2 $\alpha$ ) secretion is the apparent key to MRP in mares, and that the MRP signal(s) should exist by 14 post-ovulation to prevent endometrial PGF2 $\alpha$ from lysing the corpus luteum (Boerboom et al., 2004). Uterine fluids at day 14-16 post-ovulation contain less PGF2 $\alpha$ than cycling mares (Berglund et al., 1982). In vitro exposure of endometrial explants to embryo secretions from this time period decreased prostaglandin synthetase 2 (PTGS2) (Ealy et al., 2010). At day 18 postovulation, uterine fluids contain PGF2 $\alpha$ concentrations that are similar to cyclic mares undergoing luteolysis, suggesting that the equine embryo doesn't prevent PGF2 $\alpha$ secretion during pregnancy, but delays it (Stout and Allen, 2002). However, little is known about the actual MRP signal or group of signals. Dialysis of conditioned media from equine embryos at day 14 blastocysts and co-cultured with equine endometrial explants determined that a protein of 
1 to $6 \mathrm{kDa}$ will inhibit PGF2 $\alpha$ synthesis (Sharp et al., 1989). Others report that the anti-luteolytic activity released by embryos was refractile to proteinase treatment but was removed by charcoal treatment, indicating that the proposed MRP was a lipophilic, non-polar compound (Ababneh et al., 2000). One cannot discount, however, the possibility that two or more MRP signals exist in the mare. The trophectoderm (i.e. outermost layer of embryonic cells) synthesizes and releases both cytokines and hormones during the MRP timeframe, and apparently several of these secreted factors are capable of suppressing PGF2 $\alpha$ secretion. The question that remains unanswered is to decipher which signal or set of signals are essential for the establishment of pregnancy.

Cytokines and growth factors within the uterine microenvironment support the growth and development of the conceptus prior to implantation. In other species, many of these same signaling molecules also facilitate MRP either directly by affecting the expression of the MRP signal or indirectly by promoting embryogenesis, and specifically early placental development (Spencer et al., 2004). For example, culture of bovine blastocysts with fibroblast growth factor 2 (FGF2) causes an increase in the production and release of interferon tau (IFNT), the MRP factor for ruminants (Michael et al., 2006; Cooke et al., 2009). Other endometrial factors, such as epidermal growth factor (EGF) and insulin-like growth factor 1 (IGF1) stimulate bovine trophoblast cell proliferation and increase bovine blastocyst size (Dilly et al., 2010; Xie et al., 2017; Mesalam et al., 2018). Also, treatment of early stage embryos with IGF-1 initiates intracellular signals that protect the developing blastocyst from an environmental heat insult (Bonilla et al., 2011). The mare's endometrium produces FGF2 (de Ruijter-Villani et al., 2013), VEGF (Silva et al., 2011), EGF (Allen et al., 2017), IGF-1 and IGF-2 (Sessions-Bresnahan et al., 2018) as well as the cytokines LIF (de Ruijter-Villani et al., 2015), IL6, TNF $\alpha$ and IL1 $\beta$ 
(Sessions-Bresnahan et al., 2018). Their participation and requirement in early embryogenesis in the horse remain undefined.

We propose that describing how various endometrial-derived growth factors influence trophoblast cell proliferation and prostaglandin gene expression may provide new clues into the embryo-derived mechanisms that control MRP in horses. Our hypothesis was tested using iTr cells, an equine trophoblast cell line created through a partial cellular reprogramming event, that is similar in morphology to trophoblast cells and share a common genetic signature with native trophectoderm (TE) (Reinholt et al., 2017).

\section{MATERIALS AND METHODS}

\section{Animals and biopsy}

All animal protocols were reviewed and approved by the Virginia Polytechnic Institute and State University Institutional Animal Care and Use Committee. Mares $(\mathrm{n}=3)$ were evaluated daily by transrectal ultrasonography to map follicular development and ovulation. Mares were sedated (Xylazine, MWI Animal Health, Boise, ID) prior to biopsy collection. Endometrial biopsies were recovered at day 7 post-ovulation by insertion of a sterile alligator-type biopsy device through the cervix into the uterus and physical resection of tissue ( $75 \mathrm{mg})$. Tissue was briefly rinsed with ice-cold sterile phosphate buffered saline (PBS) and snap frozen in liquid nitrogen for RNA isolation.

\section{Cell Culture}

Induced trophoblasts (iTr) were cultured on tissueware coated with extracellular matrix (Matrigel, Corning, Corning, NY) in high glucose Dulbecco's modified Eagle medium (DMEM) supplemented with $10 \mathrm{mM}$ non-essential amino acids, 15\% fetal bovine serum (FBS), $2 \mathrm{~mm}$ glutamine, $1 \%$ penicillin-streptomycin, $0.5 \%$ gentamicin and $55 \mu \mathrm{M} \beta$-mercaptoethanol. All media and supplements were purchased from Invitrogen (Thermofisher, Carlsbad, CA). For the 
measurement of proliferation, cells were serum starved overnight followed by treatment with 10 ng/mL bovine FGF2, human EGF, human HGF or human IGF-1 for $24 \mathrm{hr}$. Growth factors were purchased from R\&D Systems (Minneapolis, MN). During the final $2 \mathrm{~h}$ of culture, $10 \mu \mathrm{M} 5$ ethynyl-2'-deoxyuridine (EdU) was included for the detection of DNA synthesis. Chemical inhibition of AKT serine/threonine kinase 1 (AKT1) or mitogen-activated protein kinase kinase 1 and 2 (MEK1/2) was accomplished by supplementation of the culture media with $1 \mathrm{nM}$ MK2206 and $1 \mathrm{nM}$ PD0325901, respectively. Cells were fixed with 4\% paraformaldehyde in PBS and EdU was detected by click chemistry (Click-iT EdU AlexaFluor 488, Invitrogen). Nuclei were detected following incubation with $10 \mu \mathrm{g} / \mathrm{mL}$ Hoechst 33245 (Invitrogen). Total nuclei and EdU-positive nuclei were visualized with epifluorescence (Eclipse TS100, Nikon, Melville, NY) and representative images captured with a CoolSNAP HQ2 camera (Photometrics, Tucson, AZ) with shutter speed controlled by NIS Elements software (Nikon). A mitotic index was calculated as $\operatorname{EdU}(+) /$ Hoechst(+) X 100.

\section{RNA isolation and polymerase chain reaction (PCR)}

Total RNA was extracted and purified from iTr cells and endometrial tissue using TRIzol (Ambion, Austin, TX). Contaminating DNA was removed with DNase I (Ambion). A High Capacity cDNA Reverse Transcription Kit (ThermoFisher) was used to convert RNA into cDNA, according to the manufacturer's instructions. Real-time PCR reactions were performed with Power SYBR ${ }^{\circledR}$ Green PCR Master Mix (ThermoFisher) and gene specific primers (Table 1) using an Eppendorf Realplex thermocycler (Eppendorf, Hamburg, Germany). The fold change for all the samples was calculated using the $2^{-\triangle \Delta \mathrm{Ct}}$ method. Glyceraldehyde 3-phosphate dehydrogenase (GAPDH) was used as an internal control; GAPDH Ct values were unaffected by treatment. Verification that a single amplicon was produced was completed by electrophoresis through 2\% agarose gels impregnated with SYBR Safe DNA gel stain (Thermofisher) in $40 \mathrm{mM}$ 
Tris-acetate buffer ( $\mathrm{pH} 8.3$ ) containing $1 \mathrm{mM}$ ethylenediaminetetraacetic acid. Amplicons were visualized at $280 \mathrm{~nm}$ on a BioDoc-It (UVP).

\section{Western Blot}

Cells were washed with ice-cold PBS and lysed with radioimmunoprecipitation assay (RIPA; Thermofisher) buffer containing protease and phosphatase inhibitors (Halt; Thermofisher). Insoluble material was removed by centrifugation at $10,000 \mathrm{Xg}$ for 5 minutes at 4 C. Protein concentration was measured colorimetrically (BCA Assay, Thermofisher). Proteins were diluted in loading buffer containing SDS (LDS, Thermofisher) and heated at $95{ }^{\circ} \mathrm{C}$ for 5 min. Equivalent amounts of protein were electrophoretically separated through denaturing 10\% polyacrylamide gels (NuPAGE, Thermofisher). Proteins were transferred to nitrocellulose (iBlot2 Dry Transfer, Thermofisher). Membranes were incubated with 10 mM TRIS, pH 8.0, $150 \mathrm{mM} \mathrm{NaCl}$ (TBS) containing 2\% bovine serum albumin (BSA) and 0.1\% Tween20 (TBST) for $30 \mathrm{~min}$ at room temperature to block nonspecific antigen sites. Subsequently, membranes were incubated at $4{ }^{\circ} \mathrm{C}$ overnight with anti-AKT1 (pan 11E7; Cell Signaling Technologies (CST), Danvers, MD), anti-phosphoAKT1 ${ }^{\mathrm{S} 473}$ (D9E; CST), anti-ERK1/2 (137F5; CST), antiphosphoERK1/2 (197G2; CST) or anti- $\alpha / \beta$-tubulin (2148; CST) diluted 1:2,000 in TBS containing 2\% BSA. Blots were washed extensively with TBST followed by incubation with donkey anti-rabbit IgG-peroxidase (Invitrogen) diluted 1:2,000 in TBS containing 2\% BSA for 45 min at room temperature. After washing with PBS, immunocomplexes were visualized by chemiluminescence (ECL, Thermofisher) using a BioDoc-It (UVP, Upland, CA).

\section{Statistics}

Data were analyzed by one- or two-way ANOVA using Prism 7 (Graphpad Software, La Jolla, CA). Technical replicates were averaged for each biological replicate prior to calculation of means and SEM. Post-test comparisons were performed using Tukey's adjustment to analyze 
pre-planned comparisons between groups. A minimum of 3 replicates of each experiment was performed. Significance was set at $P<0.05$.

\section{RESULTS}

Equine iTr cells express receptors for EGF, FGF, HGF and IGF-1 (Reinholt et al., 2017). Expression of the corresponding ligands was examined by RT-PCR using total RNA isolated from the uterine endometrium, archived adult liver tissue and iTr cells. Expression of $E G F$, $F G F 2, H G F$ and $I G F-1$ was detected in endometrium and liver (positive control) RNA isolates

(Fig 2-1). Expression of $E G F, F G F 2$ and $I G F-1$ was detected in iTr cells whereas HGF was not detected.

Each growth factor docks with its cognate receptor tyrosine kinase (RTK) and initiates several intracellular signals that modify cell behavior. As a first step to ensure that the ligands can affect iTr biology, each growth factor was examined for its ability to phosphorylate AKT1 and ERK1/2, two prominent intracellular signaling effectors of RTKs. Serum-starved equine iTr cells were treated with recombinant EGF, FGF2, HGF or IGF-1 and analyzed with total and phospho-specific antibodies to AKT1 and ERK1/2. Weak phosphorylation of AKT1 was observed in response to EGF, FGF2, HGF or IGF-1 exposure. By contrast, substantial amounts of phosphorylated ERK1/2 were detected following treatment with EGF, FGF2 and HGF (Fig 22). Direct phosphorylation of ERK1/2 in response to IGF-I was no different than control. No differences in the relative amounts of total AKT, ERK1/2 or $\alpha / \beta$ tubulin proteins were noted. Initial experiments examined the role of AKT1 as a mediator of iTr proliferation. In brief, equine iTr cells were treated with each growth factor in the presence or absence of the AKT inhibitor, MK2206. Weak phosphorylation of AKT1 ${ }^{\mathrm{S} 473}$ occurred in response to EGF, FGF2, HGF and IGF-1 (Fig 2-3A). Phosphorylation was inhibited completely by inclusion of $1 \mathrm{nM}$ MK2206 in the culture media. The next experiment examined whether these growth factors 
influence iTr proliferation. Results revealed that EGF, FGF2, HGF and IGF-1 increased $(P<$ 0.05 ) the percentage of cells incorporating EdU (Fig 2-3B). Supplementation of the culture media with the individual growth factors and $10 \mathrm{nM}$ MK2206 suppressed $(P<0.05) \mathrm{EGF}$, HGF and IGF-1-directed proliferation. The AKT inhibitor affected neither control nor FGF2-mediated cell division.

The importance of ERK1/2 signals as mediators of mitogenic effects was evaluated. Phosphorylation of ERK1/2 occurred in response to EGF, FGF2, HGF and IGF-1, although to varying intensity levels. Supplementation with $1 \mathrm{nM}$ PD0325901 suppressed $(P<0.05)$ both basal and growth factor-initiated phosphorylation of ERK1/2 (Fig 2-4A) as well as proliferation (Fig 2-4B).

A final set of studies examined whether the growth factors under investigation affect gene expression of enzymes controlling prostaglandin E2 and F2 $\alpha$ production. Treatment of $i \operatorname{Tr}$ with either EGF, FGF2, HGF or IGF-1 failed to alter basal transcript amounts for cytochrome P450 family 11 subfamily A member 1 (CYP11A), prostaglandin E synthase 2 (PTGES2) and PTGES3 (Fig 2-5 A, C, D, respectively). Treatment of iTr cells with HGF caused a 10-fold increase $(P<0.05)$ in prostaglandin synthase $2(P T G S 2)$ mRNA abundance. No other growth factor elicited an effect on PTGS2 (Fig 2-5B). Media supplementation with $1 \mathrm{nM}$ MK2206 (AKT inhibitor) did not affect either basal transcription of PTGS2 or the HGF-directed response (Fig 26A). By contrast, iTr cells incubated with HGF and PD0325901 (MEK1/2 inhibitor) resulted in a reduction $(P<0.05)$ in $P T G S 2$ mRNA content to levels comparable to controls (Fig 2-6B).

\section{DISCUSSION}

The incidence of pregnancy loss in the mare is $7.9 \%$, and the majority of these losses occur within the first 42 days post-ovulation (Rose et al., 2018). The underlying causes of these losses remain largely unknown due to our limited understanding of embryology and MRP in the 
horse. Communication between the uterine endometrium and the TE of the developing blastocyst is a critical determinant in establishing pregnancy. Transcriptome analysis of the early TE reveals the presence of conventional RTK signaling systems as well as chemokine and interferon cell signaling genes (Iqbal et al., 2014; Reinholt et al., 2017).

This work determined that iTr cells can respond to FGF2. Fibroblast growth factor receptors 1, 2 and 3 are expressed in TE with a temporal increase over the initial 21 days of the pregnancy that coincide with an increase in $F G F 2$ expression within the endometrium (de Ruijter-Villani et al., 2013). Treatment of iTr cells with FGF2 caused an increase in cell proliferation, similar to that observed in bovine trophoblast cells and blastocysts (Xie et al., 2017). The ligand initiated weak phosphorylation of AKT1, and AKT1 was not involved in either mitotic responses or steroidogenesis enzyme expression in equine iTr cells. Thus, the intracellular signaling pathway used by FGF2 for equine trophoblast proliferation remains unknown. It is possible that FGF2 utilizes ERK1/2-dependent pathways, but we were unable to tease apart mitosis in the absence of ERK1/2 activity, which is an absolute requirement for iTr cell division.

Insulin-like growth factor-1 contributes to multiple events in early embryogenesis and trophoblast biology specifically. Treatment of primary TE cells isolated from day 12 porcine embryos with an equivalent amount of IGF $(20 \mathrm{ng} / \mathrm{mL})$ does not affect proliferation but does promote migration (Jeong et al., 2014). Proliferation was increased by $60 \%$ over controls, however, by treatment of porcine trophoblasts with $100 \mathrm{ng} / \mathrm{mL}$. The IGF-1 mediated effect on mitosis was abolished by chemical inhibition of PI3K, mammalian target of rapamycin (mTOR), MEK1/2 and p38 directed signaling events. This suggests that a complex kinase network regulates porcine trophoblast proliferation. Because we examined the effects of a single IGF-1 concentration, it is possible that mitogenic effects could occur at greater concentrations as seen 
with porcine trophoblasts. Indeed, $50 \mathrm{ng} / \mathrm{mL}$ of IGF-1 is required to elicit a mitogenic effect on bovine CT1 trophoblast cells (Xie et al., 2017). Future efforts should include examination of greater concentrations of IGF-1 on iTr biology as well as measurement of IGF-1 content in the uterine milieu.

Ligand-initiated receptor recruitment of PI3Ks to the plasma membrane followed by AKT phosphorylation and formation of the PI3K/AKT/mTOR signalosome underlies cell proliferation, metabolism and growth (Laplante and Sabatini, 2012). Ablation of individual components (PI3K p110 $\alpha$, PI3K p110 $\beta$, mTORC) and downstream effectors (Sin1) of the signaling module is embryonic lethal in mice (Jason and Cui, 2016). Activation of the module by EGF and HGF triggers equine iTr proliferation and offers a potential pathway for early embryo development in the horse. In support of this premise, EGF improves bovine embryo quality in a serum-free media in vitro (Mesalam et al., 2018). Culture of bovine blastocysts with EGF affected neither total blastomere number nor $\mathrm{CDX} 2(+)$ trophoblast numbers but worked synergistically with FGF2 and IGF-I to increase both parameters (Xie et al., 2017). Proliferation of trophoblast cells derived from bovine placentomes is increased by EGF treatment through a pathway that involves both ERK1/2 and PI3K activity (Dilly et al., 2010). The discrepant results likely reflect differences in developmental age of the cell types.

The most striking result of the experiments was the observation that HGF initiated ERK1/2 signals and this resulted in a 10-fold increase in PTGS2 expression. The enzymatic actions of PTGS2 convert arachidonic acid to PGH2, a precursor to PGE2 and PGF2 $\alpha$. Equine embryos secrete and release PGs into the uterine milieu, and this contributes to smooth muscle contraction within the uterus and subsequent embryo mobility (Watson and Sertich, 1989; Stout and Allen, 2002). Inhibition of PTGS2 does not affect uterine tone but substantially reduces 
embryo motility within the uterus in mares (Stout and Allen, 2001). Our results fill a void through identification of HGF, a growth factor secreted by the uterine endometrium, as a modulator of trophoblast PTGS2 expression and subsequent PG production during early pregnancy. These actions are dependent upon the MEK/ERK signaling module. By contrast, HGF signals through the PI3K/AKT module are critical for trophoblast proliferation. The capacity to use divergent signaling networks to control distinct cellular functions makes HGF an intriguing possible modulator of MRP. During the preimplantation stage of gestation, the embryokine may support trophectoderm expansion while ensuring continued mobility prior to fixation.

Maternal recognition of pregnancy in the mare remains a mystery but likely involves endometrial derived growth factor communication with the outer trophectoderm layer of the embryo. Results presented herein provide evidence that EGF, FGF2, HGF and IGF-1 may support trophoblast proliferation during early equine embryogenesis. More importantly, HGF mediated signals uniquely affect both trophoblast proliferation and steroidogenesis gene transcription supporting a role for this endometrial-derived growth factor as a novel facilitator of MRP in the horse. 


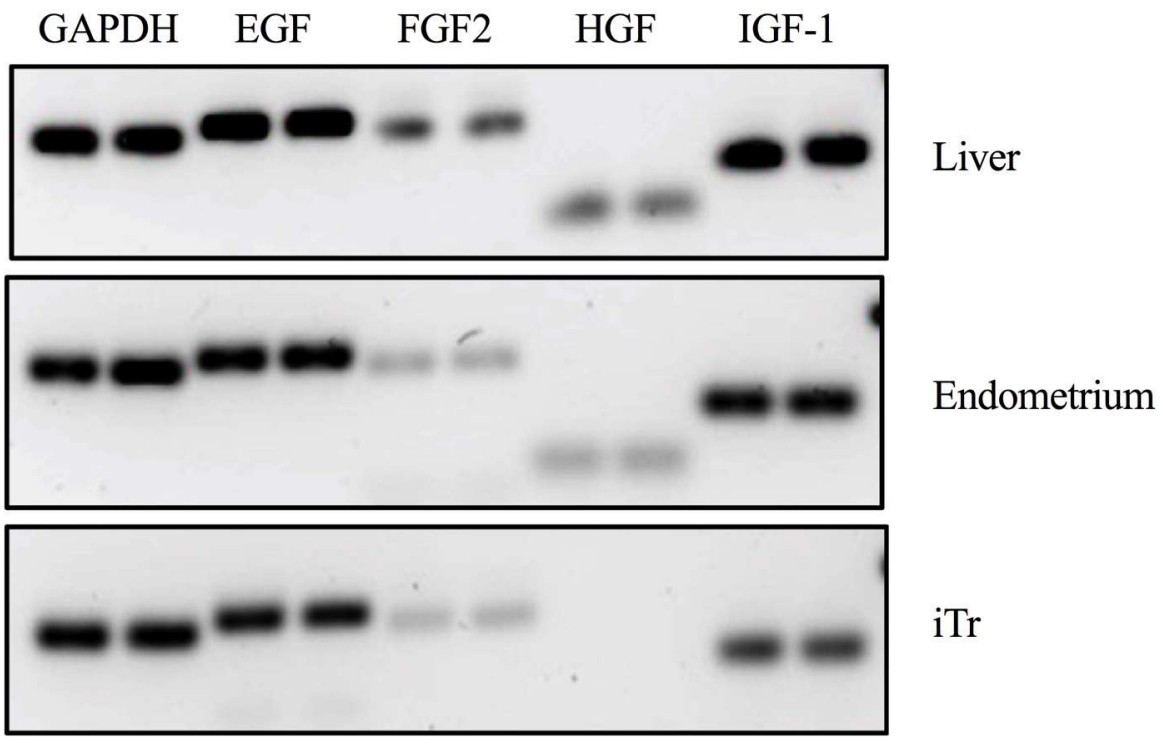

Figure 2-1. Expression of potential embryokines in equine liver, endometrium and iTr cells. Total RNA was isolated from adult mare liver and day 7 post-ovulation endometrium, and equine iTr cells, reverse transcribed and amplified with gene-specific primers for EGF, FGF2, HGF, IGF-1 and GAPDH. Amplicons were separated through Syber-safe agarose gels and imaged. Gel is representative of three independent mares. 


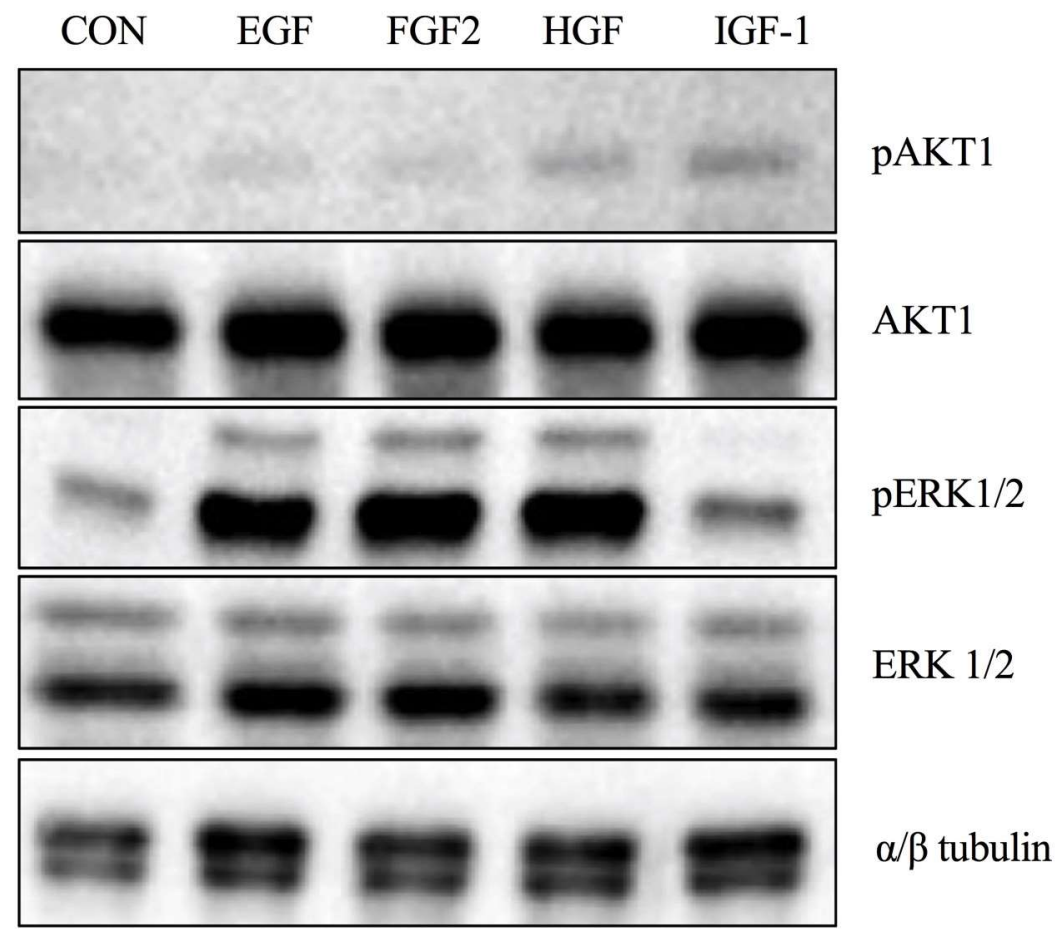

Figure 2-2. Phosphorylation of AKT1 and ERK1/2 in response to selected growth factors. Equine iTr cells were serum starved and treated with $10 \mathrm{ng} / \mathrm{mL}$ of EGF, FGF2, HGF or IGF-1 for 20 minutes prior to lysis. Proteins were separated through SDS-PAGE, transferred to nitrocellulose and analyzed by Western blot for total and phosphorylated version of AKT and ERK1/2. Tubulin expression was monitored as a loading control. 
A.

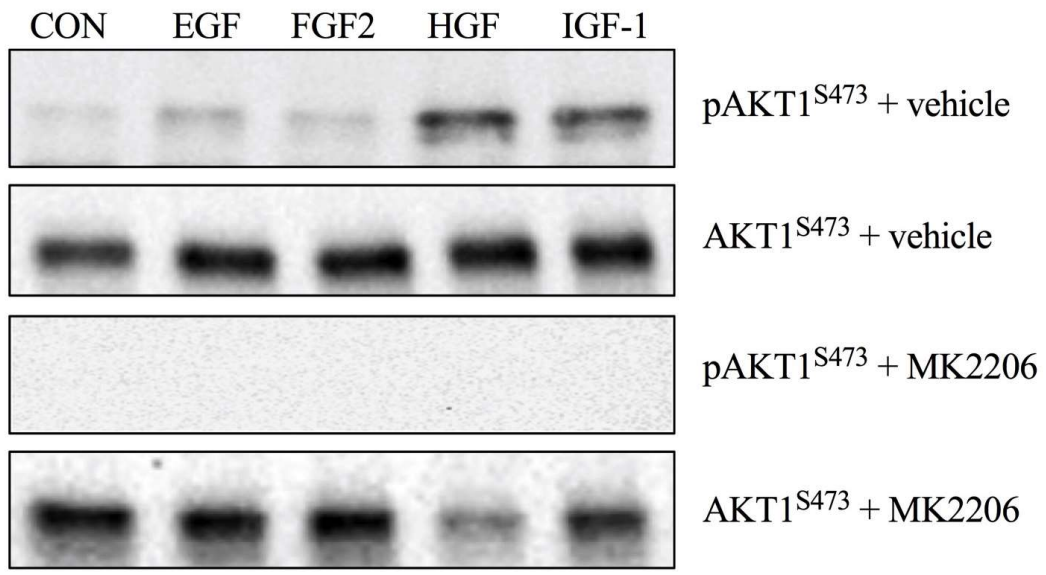

B.

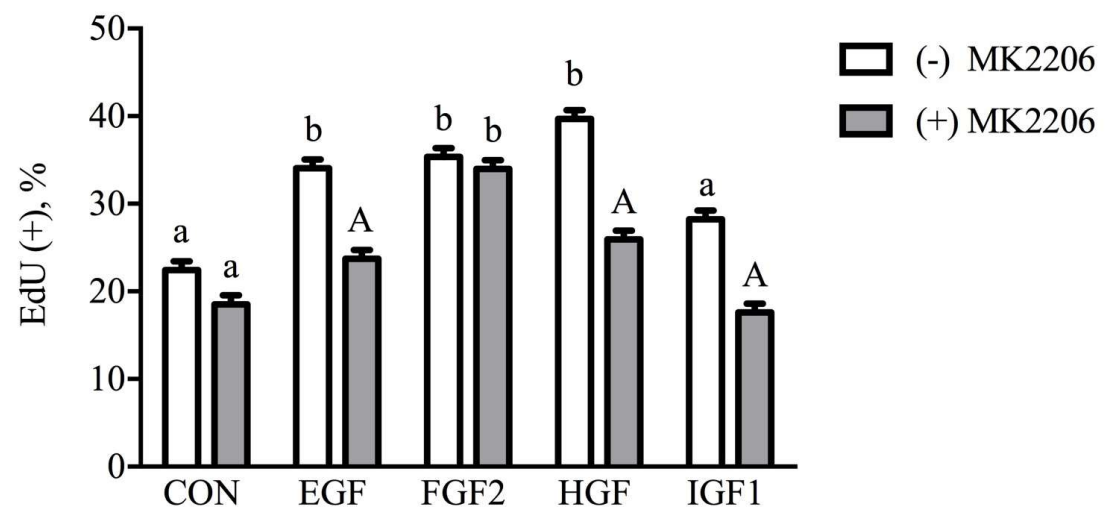

Figure 2-3. Equine iTr cells proliferate in response to EGF, HGF and IGF-1 in an AKT1dependent manner. Equine iTr cells were treated with the respective growth factors in the presence or absence of $1 \mathrm{nM}$ MK2206, an AKT inhibitor. Lysates were analyzed by Western blot for total and phosphorylated AKT1 (A). Parallel plates of cells were treated in a similar manner with EdU included 2-h prior to fixation. Total and EdU (+) cells were enumerated (B). Means and SEMs of 3 replicate experiments shown. Different letters represent significance at $P$ $<0.05$. Capital letters indicate significance within treatment at $\mathrm{P}<0.05$. 
A.

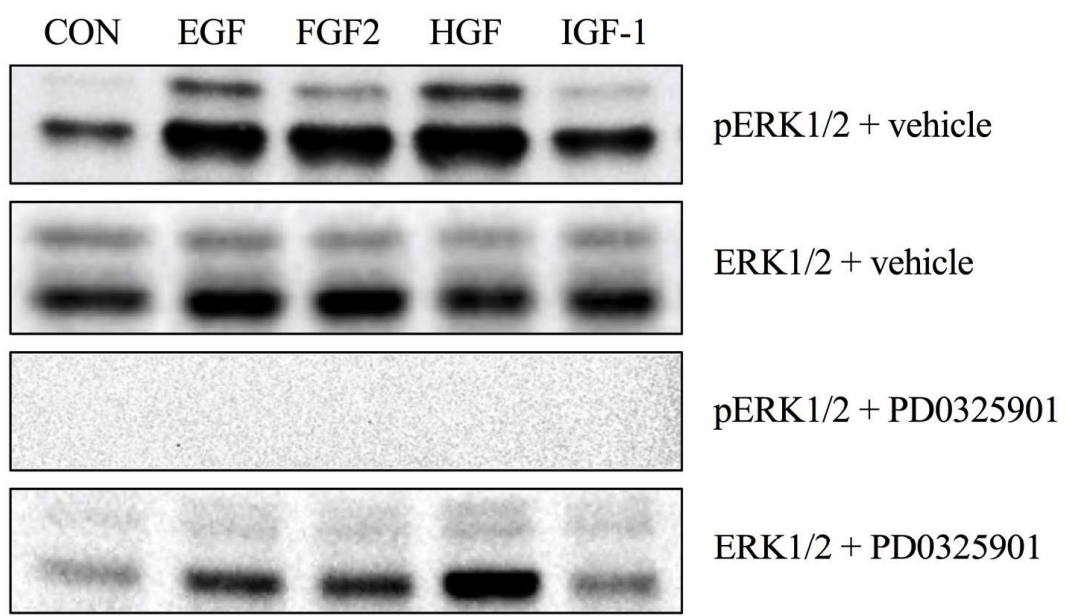

B.

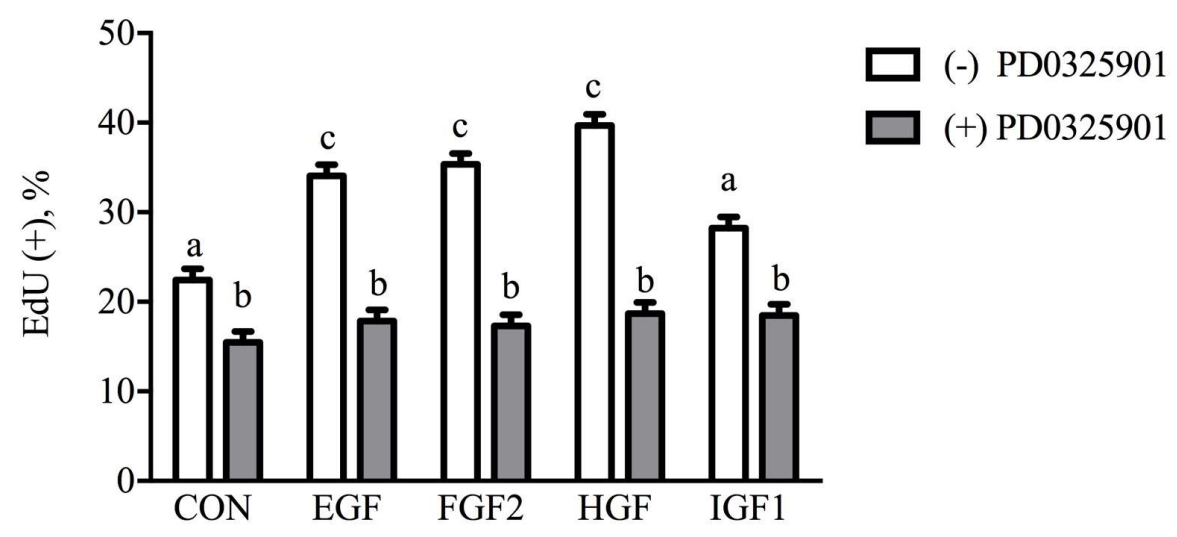

Figure 2-4. Equine iTr cells require MEK/ERK signals for proliferation. Equine iTr cells were treated with the respective growth factors in the presence or absence of $1 \mathrm{nM}$ PD0325901, a MEK inhibitor. Lysates were analyzed by Western blot for total and phosphorylated ERK1/2 (A). Parallel plates of cells were treated in a similar manner with EdU included 2-h prior to fixation. Total and EdU $(+)$ cells were enumerated $(\mathbf{B})$. Means and SEMs of 3 replicate experiments shown. Different letters represent significance at $\mathrm{P}<0.05$. 
A.

Cyp11A

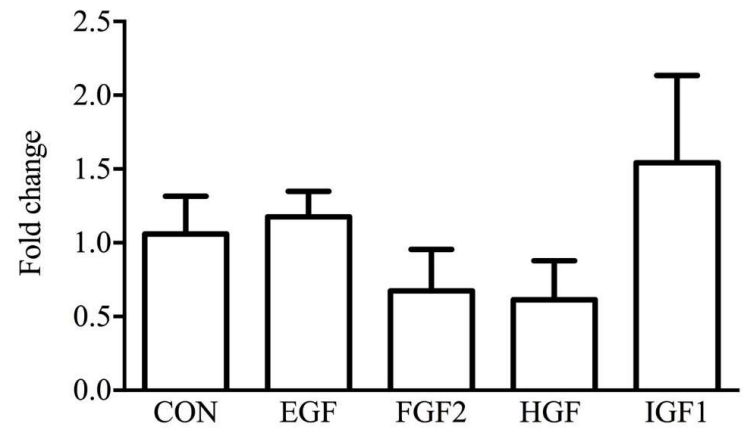

C.

PTGES2

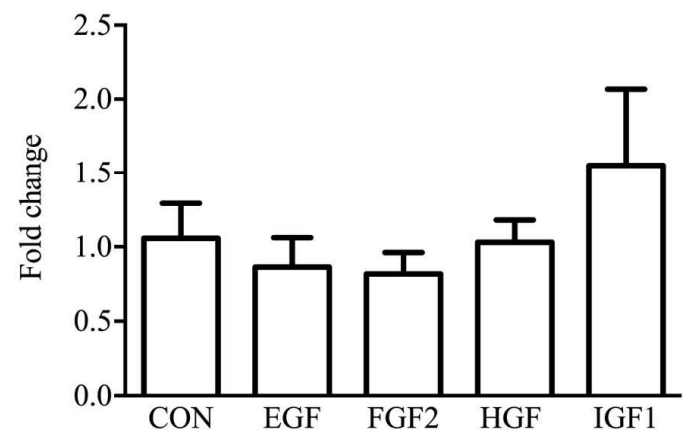

B.

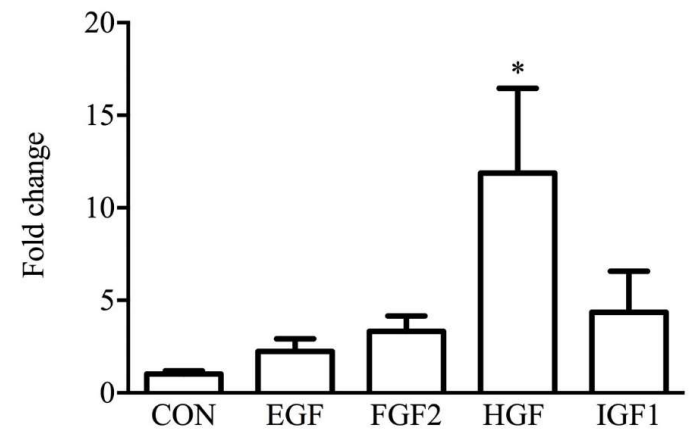

D.

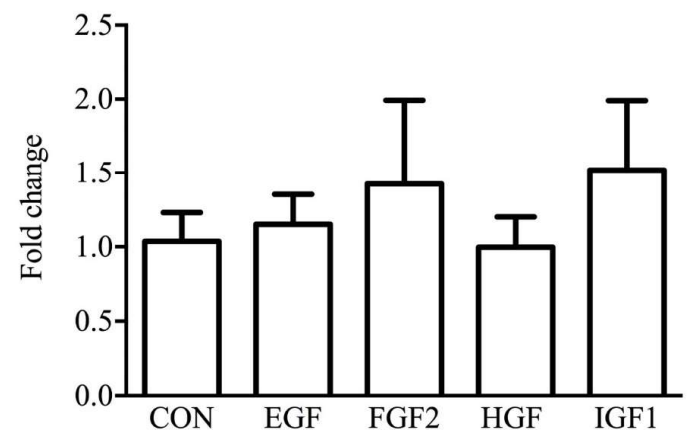

Figure 2-5. Growth factor treatment of equine iTr cells differentially affects steroidogenic gene expression. Equine iTr cells were cultured for $36 \mathrm{~h}$ with $10 \mathrm{ng} / \mathrm{mL}$ of EGF, FGF2, HGF or IGF-1. Total RNA was isolated, reverse transcribed and analyzed by real time PCR for Cyp11A, PTGS2, PTGES2 and PTGES3 mRNA abundance. Fold change calculated relative to CON cells treated with vehicle-only. Mean and SEM of 3 replicate experiments shown. * denotes significance at $\mathrm{P}<0.05$. 
A.

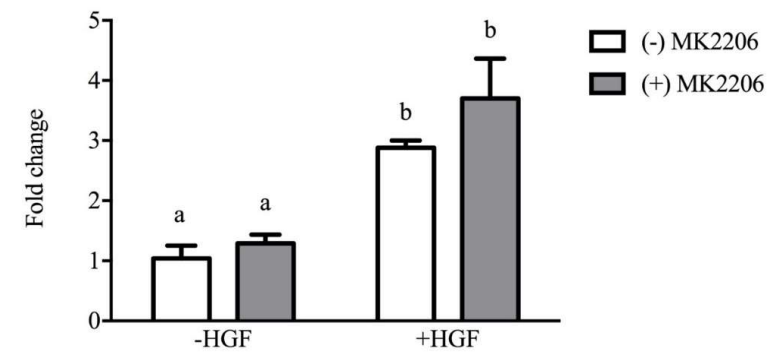

B.

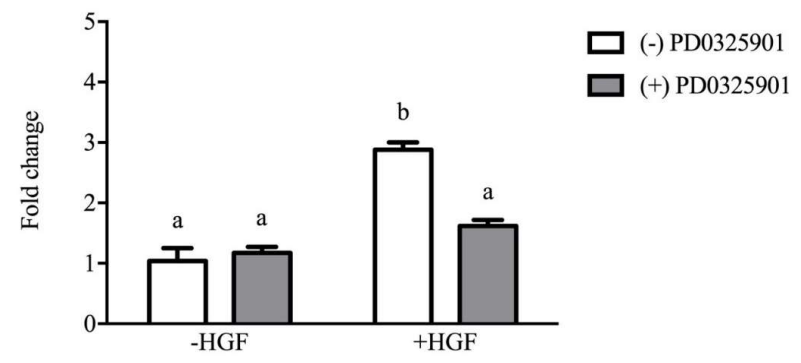

Figure 2-6. HGF stimulates PTGS2 expression through a MEK-dependent signaling pathway. Equine iTr cells were cultured for $36 \mathrm{~h}$ with $10 \mathrm{ng} / \mathrm{mL}$ of HGF in the presence or absence of $1 \mathrm{nM}$ MK2206 (A) or $1 \mathrm{nM}$ PD0325901 (B). Total RNA was isolated, reverse transcribed and analyzed by real time PCR for PTGES2 mRNA abundance. Fold change calculated relative to CON cells treated with vehicle-only. Mean and SEM of 3 replicate experiments shown. ${ }^{*}$ denotes significance at $P<0.05$. 
Table 2-1. List of equine primers

\begin{tabular}{|l|c|l|}
\hline \multicolumn{1}{|c|}{ Gene } & $\begin{array}{c}\text { Amplification } \\
\text { product (bp) }\end{array}$ & \multicolumn{1}{c|}{ Primer sequence } \\
\hline $\begin{array}{l}\text { F-GAPDH } \\
\text { R-GAPDH }\end{array}$ & 150 & $\begin{array}{l}\text { CCACCCCTAACGTGTCAGTC } \\
\text { AATCGCAGGAGACAACCTGG }\end{array}$ \\
\hline $\begin{array}{l}\text { F-CYP11A1 } \\
\text { R-CYP11A1 }\end{array}$ & 159 & $\begin{array}{l}\text { AACGTTACCGAGATGCTGGC } \\
\text { CACCATCGTGCTCGTGTCTC }\end{array}$ \\
\hline $\begin{array}{l}\text { F-CYP17A1 } \\
\text { R-CYP17A1 }\end{array}$ & 108 & $\begin{array}{l}\text { CTCTGTGGTGAAGTGGATTG } \\
\text { AGTGTTGGTGTGCGGCTGAA }\end{array}$ \\
\hline $\begin{array}{l}\text { F-CYP19A1 } \\
\text { R-CYP19A1 }\end{array}$ & 100 & $\begin{array}{l}\text { AGTGCTCCTCCCATCCCATT } \\
\text { ATCGGCCTGGTCTTCTAAT }\end{array}$ \\
\hline $\begin{array}{l}\text { F-STAR } \\
\text { R-STAR }\end{array}$ & 186 & $\begin{array}{l}\text { GAAGCTCCCCTTGAGAGTAGGA } \\
\text { CAGTTCAGCTCCTGGCCAATG }\end{array}$ \\
\hline $\begin{array}{l}\text { F-PTGS2 } \\
\text { R-PTGS2 }\end{array}$ & 188 & $\begin{array}{l}\text { GCTTGTTCCAGACGAGCAGG } \\
\text { GGGATGCCAGTGATAGAGCG }\end{array}$ \\
\hline $\begin{array}{l}\text { F-PTGES2 } \\
\text { R-PTGES2 }\end{array}$ & 164 & $\begin{array}{l}\text { TGATCTGGCTGTGTATGGCG } \\
\text { ATCTTCCGTTGCCTCTCGTC }\end{array}$ \\
\hline $\begin{array}{l}\text { F-PTGES3 } \\
\text { R-PTGES3 }\end{array}$ & 196 & $\begin{array}{l}\text { CACGTTCATTCTCCGTCCTCG } \\
\text { GCAGTCGACTCTTCTCCGTTG }\end{array}$ \\
\hline $\begin{array}{l}\text { F-EGF } \\
\text { R-EGF }\end{array}$ & 126 & $\begin{array}{l}\text { TTCTGGACTGATATGGGGATT } \\
\text { GGCATCGCACCAATACAACTT }\end{array}$ \\
\hline $\begin{array}{l}\text { F-FGF2 } \\
\text { R-FGF2 }\end{array}$ & 132 & $\begin{array}{l}\text { TGCTATGAAGGAAGATGGAAG } \\
\text { TTATACTGCCCCGTTCGTTTC }\end{array}$ \\
\hline $\begin{array}{l}\text { F-HGF } \\
\text { R-HGF }\end{array}$ & 70 & $\begin{array}{l}\text { CGCTACGAAGTCTGTGACATTCC } \\
\text { TTCCCCATTGCAGGTCATG }\end{array}$ \\
\hline $\begin{array}{l}\text { F-IGF1 } \\
\text { R-IGF1 }\end{array}$ & 89 & $\begin{array}{l}\text { GAAGCAATGGGAAAAATCAGC } \\
\text { AGGTAGAAGAGATGTGAGGAG }\end{array}$ \\
\hline
\end{tabular}




\section{CHAPTER III}

\section{Implications and future directions}

In several species prostaglandins and growth factors play a central role in the establishment of pregnancy (DeFranco, 2002; Spencer and Bazer, 2004). In horses, embryonic migration to the uterus and mobility within it, are stimulated by prostaglandins $\mathrm{E}$ and $\mathrm{F}$ and required for successful establishment of pregnancy (McDowell et al., 1988; Stout and Allen, 2002). However, the role of embryo derived prostaglandins in the MRP are still not completely characterized in the horse.

Our study revealed that HGF induced an increase in iTr proliferation and simultaneous PTGS2 gene expression. In conjunction to findings from Stout \& Allen, 2001, results of this study suggest that HGF signaling from the endometrium participates in the embryo derived PGE and PGF2a secretion, required to suppress the production of the endometrium derived PGF2a responsible for luteolysis.

Different types of growth factors such as IGF-1 and FGF-2 are involved in signaling pathways that participate in mammalian embryonic and fetal development (Klein et al., 2010). Also, EGF from the maternal endometrial gland is responsible for originating and maintaining the growth and remodeling of feto-maternal interface tissues (Allen and Stewart, 2002).

This study identified that supplementation with growth factors like EGF, HGF, FGF2 and IGF1 to the iTr cells, stimulates their proliferation. Our findings also suggest that HGF and IGF1 may play an important role in cell survival, signaling and embryonic growth, by increasing AKT1 phosphorylation, reinforcing previously reported findings in humans (Vincent et al., 2011). Similar findings were observed following EGF, FGF2, HGF and IGF-1 supplementation and consecutive ERK1/2 activation. 
The aforementioned improve our understanding of the role of such GFs in equine trophectoderm expansion during embryonic development. Findings of some roles these GFs may play in embryonic development and prostaglandin expression during MRP may provide ways to improve in vitro studies of early embryonic development. These observations can be useful in designing new approaches aimed at improving successful embryo development during in vitro fertilization and cloning. Nonetheless, such findings are not enough to propose therapeutic measures to approach mares facing issues to become pregnant or those that lose pregnancy in the first weeks of gestation.

Co-cultures of endometrial explants with equine embryos or iTr spheres, and comparison of their protein and gene expression, could allow identification of the roles of TE in MRP and more strongly validate the use of $i \operatorname{Tr}$ as an in vitro model to study MRP. In addition, comparing effect of iTr spheroids on CL persistency as a consequence of iTr derived MRP signal mimicking pregnancy could provide information of TE/iTr derived signaling. Moreover, transcriptomic and proteomic analysis of day 8-15 embryos compared with day 8-15 endometrium from pregnant and non-pregnant mares would provide a more complementary set of information regarding MRP, and seem the most logical step in future studies targeting characterization of the equine MRP.

\section{ACKNOWLEDGEMENTS}

This research was supported by the Paul Mellon Professorship fund to SEJ. 


\section{LITERATURE CITED}

Ababneh, M., H. Ababneh, and F. Shidaifat. 2011. Expression of cytosolic phospholipase A2 in equine endometrium during the oestrous cycle and early pregnancy. Reproduction in domestic animals $=$ Zuchthygiene 46: 268-274.

Ababneh, M. M., M. H. Troedsson, J. R. Michelson, and B. E. Seguin. 2000. Partial characterization of an equine conceptus prostaglandin inhibitory factor. Journal of reproduction and fertility. Supplement: 607-613.

Albihn, A. et al. 2003. Production of capsular material by equine trophoblast transplanted into immunodeficient mice. Reproduction (Cambridge, England) 125: 855-863.

Allen, W. R., and F. Stewart. 2002. Equine placentation. Reproduction, Fertility and Development 13: 623-634.

Allen, W. T., S. Gower, and S. Wilsher. 2017. Localisation of epidermal growth factor (EGF), its specific receptor (EGF-R) and aromatase at the materno-fetal interface during placentation in the pregnant mare. Placenta 50: 53-59.

Arar, S. et al. 2007. Desialylation of core type 1 O-glycan in the equine embryonic capsule coincides with immobilization of the conceptus in the uterus. Carbohydrate research 342: 1110-1115.

Arnold, C. E., and C. C. Love. 2013. Laparoscopic evaluation of oviductal patency in the standing mare. Theriogenology 79: 905-910.

Aurich, C. 2011. Reproductive cycles of horses. Animal reproduction science 124: 220-228.

Bai, Q. et al. 2012. Dissecting the first transcriptional divergence during human embryonic development. Stem cell reviews 8: 150-162.

Baker, C. B., M. H. Adams, and K. J. McDowell. 1991. Lack of expression of alpha or omega interferons by the horse conceptus. Journal of reproduction and fertility. Supplement 44: 439-443.

Battut, I., S. Colchen, F. Fieni, D. Tainturier, and J. F. Bruyas. 1997. Success rates when attempting to nonsurgically collect equine embryos at 144, 156 or 168 hours after ovulation. Equine veterinary journal. Supplement: 60-62.

Bazer, F. W., T. E. Spencer, and T. L. Ott. 1997. Interferon tau: a novel pregnancy recognition signal. American journal of reproductive immunology (New York, N.Y. : 1989) 37: 412420.

Bazer, F. W., J. L. Vallet, R. M. Roberts, D. C. Sharp, and W. W. Thatcher. 1986. Role of conceptus secretory products in establishment of pregnancy. Journal of reproduction and fertility 76: 841-850.

Behrendt-Adam, C. Y., M. H. Adams, K. S. Simpson, and K. J. McDowell. 1999. Oxytocinneurophysin I mRNA abundance in equine uterine endometrium. Domestic animal endocrinology 16: 183-192.

Berg, S. L., and O. J. Ginther. 1978. Effect of Estrogens on Uterine Tone and Life Span of the Corpus Luteum in Mares2. Journal of Animal Science 47: 203-208.

Berglund, L. A., D. C. Sharp, M. W. Vernon, and W. W. Thatcher. 1982. Effect of pregnancy and collection technique on prostaglandin F in the uterine lumen of Pony mares. Journal of reproduction and fertility. Supplement 32: 335-341.

Betteridge, K. J. 2007. Equine embryology: an inventory of unanswered questions. Theriogenology 68 Suppl 1: S9-21. 
Betteridge, K. J., M. D. Eaglesome, D. Mitchell, P. F. Flood, and R. Beriault. 1982.

Development of horse embryos up to twenty two days after ovulation: observations on fresh specimens. Journal of anatomy 135: 191-209.

Bladt, F., D. Riethmacher, S. Isenmann, A. Aguzzi, and C. Birchmeier. 1995. Essential role for the c-met receptor in the migration of myogenic precursor cells into the limb bud. Nature 376: 768-771.

Blomberg, L. A., and K. A. Zuelke. 2005. Expression analysis of the steroidogenic acute regulatory protein (STAR) gene in developing porcine conceptuses. Molecular reproduction and development 72: 419-429.

Boerboom, D. et al. 2004. Expression of key prostaglandin synthases in equine endometrium during late diestrus and early pregnancy. Biology of reproduction 70: 391-399.

Bonilla, A. et al. 2011. Developmental changes in thermoprotective actions of insulin-like growth factor-1 on the preimplantation bovine embryo. Molecular and cellular endocrinology 332: 170-179.

Brinsko, S. P., T. L. Blanchard, D. D. Varner, J. Schumacher, and C. C. Love. 2010. Manual of Equine Reproduction-E-Book. Elsevier Health Sciences.

Burns, P. D., G. A. Graf, S. H. Hayes, and W. J. Silvia. 1997. Cellular mechanisms by which oxytocin stimulates uterine PGF2 alpha synthesis in bovine endometrium: roles of phospholipases C and A2. Domestic animal endocrinology 14: 181-191.

Christenson, L. K., D. B. Farley, L. H. Anderson, and S. P. Ford. 1994. Luteal maintenance during early pregnancy in the pig: role for prostaglandin E2. Prostaglandins 47: 61-75.

Cochet, M., D. Vaiman, and F. Lefevre. 2009. Novel interferon delta genes in mammals: cloning of one gene from the sheep, two genes expressed by the horse conceptus and discovery of related sequences in several taxa by genomic database screening. Gene 433: 88-99.

Cooke, F. N., K. A. Pennington, Q. Yang, and A. D. Ealy. 2009. Several fibroblast growth factors are expressed during pre-attachment bovine conceptus development and regulate interferon-tau expression from trophectoderm. Reproduction (Cambridge, England) 137: 259-269.

de Mestre, A. M. et al. 2009. Glial cells missing homologue 1 is induced in differentiating equine chorionic girdle trophoblast cells. Biology of reproduction 80: 227-234.

de Ruijter-Villani, M., P. R. van Boxtel, and T. A. Stout. 2013. Fibroblast growth factor-2 expression in the preimplantation equine conceptus and endometrium of pregnant and cyclic mares. Theriogenology 80: 979-989.

de Ruijter-Villani, M., H. van Tol, and T. Stout. 2015. Effect of pregnancy on endometrial expression of luteolytic pathway components in the mare. Reproduction, Fertility and Development 27: 834-845.

DeFranco, D. B. 2002. Navigating steroid hormone receptors through the nuclear compartment. Molecular endocrinology (Baltimore, Md.) 16: 1449-1455.

Desmarais, J. A. et al. 2011. Trophoblast stem cell marker gene expression in inner cell massderived cells from parthenogenetic equine embryos. Reproduction (Cambridge, England) 141: 321-332.

Diecke, S., A. Quiroga-Negreira, T. Redmer, and D. Besser. 2008. FGF2 signaling in mouse embryonic fibroblasts is crucial for self-renewal of embryonic stem cells. Cells, tissues, organs 188: 52-61. 
Dilly, M., N. Hambruch, J. D. Haeger, and C. Pfarrer. 2010. Epidermal growth factor (EGF) induces motility and upregulates MMP-9 and TIMP-1 in bovine trophoblast cells. Molecular reproduction and development 77: 622-629.

Douglas, G. C., C. A. VandeVoort, P. Kumar, T. C. Chang, and T. G. Golos. 2009. Trophoblast stem cells: models for investigating trophectoderm differentiation and placental development. Endocrine reviews 30: 228-240.

Douglas, R., and O. Ginther. 1976. Concentration of prostaglandins F in uterine venous plasma of anesthetized mares during the estrous cycle and early pregnancy. Prostaglandins 11: 251-260.

Ealy, A. D., M. L. Eroh, and D. C. Sharp, 3rd. 2010. Prostaglandin H synthase Type 2 is differentially expressed in endometrium based on pregnancy status in pony mares and responds to oxytocin and conceptus secretions in explant culture. Animal reproduction science 117: 99-105.

Ezashi, T., H. Matsuyama, B. P. Telugu, and R. M. Roberts. 2011. Generation of colonies of induced trophoblast cells during standard reprogramming of porcine fibroblasts to induced pluripotent stem cells. Biology of reproduction 85: 779-787.

Gardner, R. L., and R. S. Beddington. 1988. Multi-lineage 'stem' cells in the mammalian embryo. Journal of cell science. Supplement 10: 11-27.

Gastal, M. O., E. L. Gastal, K. Kot, and O. J. Ginther. 1996. Factors related to the time of fixation of the conceptus in mares. Theriogenology 46: 1171-1180.

Geisert, R. D., M. T. Zavy, R. J. Moffatt, R. M. Blair, and T. Yellin. 1990. Embryonic steroids and the establishment of pregnancy in pigs. Journal of reproduction and fertility. Supplement 40: 293.

Ginther, O. J. 1983. Mobility of the early equine conceptus. Theriogenology 19: 603-611.

Godfrey, K. M. 2002. The role of the placenta in fetal programming-a review. Placenta 23 Suppl A: S20-27.

Goff, A. K., D. Pontbriand, and J. Sirois. 1987. Oxytocin stimulation of plasma 15-keto-13,14dihydro prostaglandin F-2 alpha during the oestrous cycle and early pregnancy in the mare. Journal of reproduction and fertility. Supplement 35: 253-260.

Goff, A. K., J. Sirois, and D. Pontbriand. 1993. Effect of oestradiol on oxytocin-stimulated prostaglandin F2 alpha release in mares. Journal of reproduction and fertility 98: 107112.

Han, X. et al. 2011. Generation of induced pluripotent stem cells from bovine embryonic fibroblast cells. Cell research 21: 1509-1512.

Hartt, L. S. et al. 2005. Temporal and spatial associations of oestrogen receptor alpha and progesterone receptor in the endometrium of cyclic and early pregnant mares. Reproduction (Cambridge, England) 130: 241-250.

Hayes, M. A. et al. 2008. Proteins associated with the early intrauterine equine conceptus. Reproduction in domestic animals = Zuchthygiene 43 Suppl 2: 232-237.

Hofland, J. et al. 2010. Evidence of limited contributions for intratumoral steroidogenesis in prostate cancer. Cancer research 70: 1256-1264.

Home, P. et al. 2009. GATA3 is selectively expressed in the trophectoderm of peri-implantation embryo and directly regulates $\mathrm{Cdx} 2$ gene expression. The Journal of biological chemistry 284: 28729-28737.

$\mathrm{Hu}, \mathrm{D}$, and J. C. Cross. 2010. Development and function of trophoblast giant cells in the rodent placenta. The International journal of developmental biology 54: 341-354. 
Iqbal, K., J. L. Chitwood, G. A. Meyers-Brown, J. F. Roser, and P. J. Ross. 2014. RNA-seq transcriptome profiling of equine inner cell mass and trophectoderm. Biology of reproduction 90: 61.

Jason, S., and W. Cui. 2016. Proliferation, survival and metabolism: the role of $\mathrm{PI} 3 \mathrm{~K} / \mathrm{AKT} / \mathrm{mTOR}$ signalling in pluripotency and cell fate determination. Development (Cambridge, England) 143: 3050-3060.

Jeong, W., G. Song, F. W. Bazer, and J. Kim. 2014. Insulin-like growth factor I induces proliferation and migration of porcine trophectoderm cells through multiple cell signaling pathways, including protooncogenic protein kinase 1 and mitogen-activated protein kinase. Molecular and cellular endocrinology 384: 175-184.

Ka, H., T. E. Spencer, G. A. Johnson, and F. W. Bazer. 2000. Keratinocyte growth factor: expression by endometrial epithelia of the porcine uterus. Biology of reproduction 62: 1772-1778.

Klein, C. 2015. Novel equine conceptus?endometrial interactions on Day 16 of pregnancy based on RNA sequencing. Reproduction, fertility, and development.

Klein, C., K. E. Scoggin, A. D. Ealy, and M. H. Troedsson. 2010. Transcriptional profiling of equine endometrium during the time of maternal recognition of pregnancy. Biology of reproduction 83: 102-113.

Klein, C., K. E. Scoggin, and M. H. Troedsson. 2011. The expression of interferon-stimulated gene 15 in equine endometrium. Reproduction in domestic animals $=$ Zuchthygiene 46: 692-698.

Klein, C., and M. Troedsson. 2012. Equine pre-implantation conceptuses express neuraminidase 2--a potential mechanism for desialylation of the equine capsule. Reproduction in domestic animals = Zuchthygiene 47: 449-454.

Klein, C., and M. H. Troedsson. 2011a. Transcriptional profiling of equine conceptuses reveals new aspects of embryo-maternal communication in the horse. Biology of reproduction 84: 872-885.

Klein, C., and M. H. T. Troedsson. 2011b. Maternal recognition of pregnancy in the horse: a mystery still to be solved. Reproduction, Fertility and Development 23: 952-963.

Klohonatz, K. M. et al. 2015. Equine endometrial gene expression changes during and after maternal recognition of pregnancy. J Anim Sci 93: 3364-3376.

Laplante, M., and D. M. Sabatini. 2012. mTOR signaling in growth control and disease. Cell 149: 274-293.

Li, X., S. Zhou, M. P. Imreh, L. Ährlund-Richter, and W. Allen. 2006. Horse embryonic stem cell lines from the proliferation of inner cell mass cells. Stem cells and development 15: 523-531.

Massabbal, E. et al. 2005. PLAC1 expression increases during trophoblast differentiation: evidence for regulatory interactions with the fibroblast growth factor-7 (FGF-7) axis. Molecular reproduction and development 71: 299-304.

McDowell, K. J., M. H. Adams, C. Y. Adam, and K. S. Simpson. 1999. Changes in equine endometrial oestrogen receptor alpha and progesterone receptor mRNAs during the oestrous cycle, early pregnancy and after treatment with exogenous steroids. Journal of reproduction and fertility $117: 135-142$.

McDowell, K. J., D. C. Sharp, W. Grubaugh, W. W. Thatcher, and C. J. Wilcox. 1988. Restricted conceptus mobility results in failure of pregnancy maintenance in mares. Biology of reproduction 39: 340-348. 
McKinnon, A., E. Carnevale, E. Squires, N. Carney, and G. Seidel. 1989. Bisection of equine embryos. Equine Veterinary Journal 21: 129-133.

Mesalam, A. et al. 2018. A combination of bovine serum albumin with insulin-transferrinsodium selenite and/or epidermal growth factor as alternatives to fetal bovine serum in culture medium improves bovine embryo quality and trophoblast invasion by induction of matrix metalloproteinases. Reproduction, Fertility and Development.

Murakami, M. et al. 1998. The functions of five distinct mammalian phospholipase A2S in regulating arachidonic acid release. Type IIa and type V secretory phospholipase A2S are functionally redundant and act in concert with cytosolic phospholipase A2. The Journal of biological chemistry 273: 14411-14423.

Neely, D. P., G. H. Stabenfeldt, and C. L. Sauter. 1979. The effect of exogenous oxytocin on luteal function in mares. Journal of reproduction and fertility 55: 303-308.

Oriol, J. G., K. J. Betteridge, A. J. Clarke, and F. J. Sharom. 1993. Mucin-like glycoproteins in the equine embryonic capsule. Molecular reproduction and development 34: 255-265.

Paul, S., and P. Home. 2015. Combinatorial functions of GATA2 and GATA3 are essential for early trophoblast development and to balance the stem vs. differentiation and angiogenic equilibrium in trophoblast lineage. Placenta 36: A34.

Pfeffer, P. L., and D. J. Pearton. 2012. Trophoblast development. Reproduction (Cambridge, England) 143: 231-246.

Phillips, R. J., M. A. Fortier, and A. Lopez Bernal. 2014. Prostaglandin pathway gene expression in human placenta, amnion and choriodecidua is differentially affected by preterm and term labour and by uterine inflammation. BMC pregnancy and childbirth 14: 241.

Pratt, B. R., R. L. Butcher, and E. K. Inskeep. 1977. Antiluteolytic effect of the conceptus and of PGE2 in ewes. J Anim Sci 45: 784-791.

Ralston, A. et al. 2010. Gata3 regulates trophoblast development downstream of Tead4 and in parallel to Cdx2. Development (Cambridge, England) 137: 395-403.

Reinholt, B. M., J. S. Bradley, R. D. Jacobs, A. D. Ealy, and S. E. Johnson. 2017. Tissue organization alters gene expression in equine induced trophectoderm cells. General and comparative endocrinology 247: 174-182.

Rielland, M., I. Hue, J. P. Renard, and J. Alice. 2008. Trophoblast stem cell derivation, crossspecies comparison and use of nuclear transfer: new tools to study trophoblast growth and differentiation. Developmental biology 322: 1-10.

Rossant, J. 2007. Stem cells and lineage development in the mammalian blastocyst. Reproduction, fertility, and development 19: 111-118.

Russ, A. P. et al. 2000. Eomesodermin is required for mouse trophoblast development and mesoderm formation. Nature 404: 95-99.

Saito, S. et al. 2002. Isolation of embryonic stem-like cells from equine blastocysts and their differentiation in vitro. FEBS letters 531: 389-396.

Scherzer, J. 2010. Enhancing reproductive performance in mares. Compendium (Yardley, PA) 32: E1-7; quiz E7.

Scott, I. C., L. Anson-Cartwright, P. Riley, D. Reda, and J. C. Cross. 2000. The HAND1 basic helix-loop-helix transcription factor regulates trophoblast differentiation via multiple mechanisms. Molecular and cellular biology 20: 530-541.

Sessions-Bresnahan, D. R., A. L. Heuberger, and E. M. Carnevale. 2018. Obesity in mares promotes uterine inflammation and alters embryo lipid fingerprints and homeostasis. Biology of reproduction. 
Sharp, D. C., K. J. McDowell, J. Weithenauer, and W. W. Thatcher. 1989. The continuum of events leading to maternal recognition of pregnancy in mares. Journal of reproduction and fertility. Supplement 37: 101-107.

Sharp, D. C., M. J. Thatcher, M. E. Salute, and A. R. Fuchs. 1997. Relationship between endometrial oxytocin receptors and oxytocin-induced prostaglandin F2 alpha release during the oestrous cycle and early pregnancy in pony mares. Journal of reproduction and fertility 109: 137-144.

Short, R. 1969. Implantation and the maternal recognition of pregnancy. Foetal Autonomy 2: 31.

Silva, L. A., C. Klein, A. D. Ealy, and D. C. Sharp. 2011. Conceptus-mediated endometrial vascular changes during early pregnancy in mares-An anatomic, histomorphometric and vascular endothelial growth factor receptor system immunolocalization and gene expression study. Reproduction (Cambridge, England): REP-11-0149.

Simpson, K. S., M. H. Adams, C. Y. Behrendt-Adam, C. B. Baker, and K. J. McDowell. 1999. Identification and initial characterization of calcyclin and phospholipase A2 in equine conceptuses. Molecular reproduction and development 53: 179-187.

Spencer, T. E., and F. W. Bazer. 1995. Temporal and spatial alterations in uterine estrogen receptor and progesterone receptor gene expression during the estrous cycle and early pregnancy in the ewe. Biology of reproduction 53: 1527-1543.

Spencer, T. E., and F. W. Bazer. 2004. Conceptus signals for establishment and maintenance of pregnancy. Reproductive Biology and Endocrinology 2: 49.

Stewart, F. 1996. Roles of mesenchymal-epithelial interactions and hepatocyte growth factorscatter factor (HGF-SF) in placental development. Reviews of reproduction 1: 144-148.

Stout, T., and W. Allen. 2002. Prostaglandin E(2) and F(2 alpha) production by equine conceptuses and concentrations in conceptus fluids and uterine flushings recovered from early pregnant and dioestrous mares. Reproduction (Cambridge, England) 123: 261-268.

Stout, T. A., S. Meadows, and W. R. Allen. 2005. Stage-specific formation of the equine blastocyst capsule is instrumental to hatching and to embryonic survival in vivo. Animal reproduction science 87: 269-281.

Strumpf, D. et al. 2005. Cdx2 is required for correct cell fate specification and differentiation of trophectoderm in the mouse blastocyst. Development (Cambridge, England) 132: 20932102.

Tremoleda, J. L. et al. 2003. Effects of in vitro production on horse embryo morphology, cytoskeletal characteristics, and blastocyst capsule formation. Biology of reproduction 69: 1895-1906.

Tu, L. N. et al. 2014. Peripheral benzodiazepine receptor/translocator protein global knock-out mice are viable with no effects on steroid hormone biosynthesis. The Journal of biological chemistry 289: 27444-27454.

Vanderwall, D. K., G. L. Woods, J. A. Weber, and A. B. Lichtenwalner. 1994. Corpus luteal function in nonpregnant mares following intrauterine administration of prostaglandin E2 or estradiol-17 $\beta$. Theriogenology 42: 1069-1083.

Vincent, E. E. et al. 2011. Akt phosphorylation on Thr308 but not on Ser473 correlates with Akt protein kinase activity in human non-small cell lung cancer. British Journal of Cancer 104: 1755-1761.

Walters, K. W., J. F. Roser, and G. B. Anderson. 2001. Maternal-conceptus signalling during early pregnancy in mares: oestrogen and insulin-like growth factor I. Reproduction (Cambridge, England) 121:331-338. 
Watson, E. D., and P. L. Sertich. 1989. Prostaglandin production by horse embryos and the effect of co-culture of embryos with endometrium from pregnant mares. Journal of reproduction and fertility $87: 331-336$.

Weber, J. A., D. A. Freeman, D. K. Vanderwall, and G. L. Woods. 1991. Prostaglandin E2 hastens oviductal transport of equine embryos. Biology of reproduction 45: 544-546.

Weber, J. A., G. L. Woods, D. A. Freeman, and D. K. Vanderwall. 1992. Prostaglandin E2 secretion by day-6 to day-9 equine embryos. Prostaglandins 43: 55-59.

Wilsher, S., and W. R. Allen. 2011. Intrauterine administration of plant oils inhibits luteolysis in the mare. Equine Vet J 43: 99-105.

Woodley, S. L., P. J. Burns, R. H. Douglas, and W. D. Oxender. 1979. Prolonged interovulatory interval after oestradiol treatment in mares. Journal of reproduction and fertility. Supplement: 205-209.

Xie, M., S. R. McCoski, S. E. Johnson, M. L. Rhoads, and A. D. Ealy. 2017. Combinatorial effects of epidermal growth factor, fibroblast growth factor 2 and insulin-like growth factor 1 on trophoblast cell proliferation and embryogenesis in cattle. Reproduction, Fertility and Development 29: 419-430.

Yamanaka, Y., F. Lanner, and J. Rossant. 2010. FGF signal-dependent segregation of primitive endoderm and epiblast in the mouse blastocyst. Development (Cambridge, England) 137: 715-724. 